\title{
Grafos evolutivos na modelagem e análise de redes dinâmicas
}

\author{
Paulo Henrique Floriano
}

\author{
DisSERTAÇÃO APRESENTADA \\ $\mathrm{AO}$ \\ Instituto De Matemática e Estatística \\ DA \\ Universidade DE SÃo Paulo \\ PARA \\ OBTENÇÃO DO TÍTULO \\ $\mathrm{DE}$ \\ Mestre em CiÊnCIAS
}

Programa: Mestrado em Ciência da Computação
Orientador: Prof. Dr. Alfredo Goldman vel Lejbman

Durante o desenvolvimento deste trabalho o autor recebeu auxílio financeiro da FAPESP

São Paulo, Março de 2012 


\section{Grafos evolutivos na modelagem e análise de redes dinâmicas}

Esta dissertação contém as correções e alterações sugeridas pela Comissão Julgadora durante a defesa realizada por Paulo Henrique Floriano em 29/02/2011.

O original encontra-se disponível no Instituto de Matemática e Estatística da Universidade de São Paulo.

Comissão Julgadora:

- Prof. Dr. Alfredo Goldman vel Lejbman (orientador) - IME-USP

- Prof. Dr. José Coelho de Pina Junior - IME-USP

- Prof. Dr. Raquel Aparecida de Freitas Mini - PUC-MG 


\section{Agradecimentos}

Ao meu orientador Prof. Dr. Alfredo Goldman e co-orientadora Profa. Dra. Luciana Arantes por me incentivarem a fazer o mestrado, fornecerem as ideias e os recursos para executá-las.

Aos meus pais Sílvia e José Carlos, minha avó Alice e meu irmão João Carlos pela boa educação, incentivo, confiança, e apoio em todos os momentos. Nada em minha vida seria possível sem vocês. Obrigado!

Aos meus amigos de infância que sempre fizeram parte dos momentos mais divertidos e também nunca decepcionaram nas horas difíceis.

Aos meus amigos do IME-USP pelas contribuições com ideias, com apoio em todas as situações e por muitos bons momentos ao lado de vocês.

A todas as outras pessoas que me ofereceram e oferecem apoio nos momentos difíceis, em especial à Evelyn Farias, cuja companhia, mesmo distante, passou a ser um incentivo para a minha vida.

Agradeço à FAPESP (Fundação de Amparo à Pesquisa do Estado de São Paulo) pelo apoio financeiro a esta pesquisa. 


\section{Resumo}

Atualmente, muitas redes com características dinâmicas estão em funcionamento (por exemplo MANETs, DTNs, redes oportunistas, etc). Neste trabalho, estudamos um modelo para estas redes chamado de Grafos Evolutivos, que permite expressar a dinamicidade das conexões entre nós por meio de uma simples extensão da estrutura comum de grafos. Esta modelagem é utilizada no arcabouço proposto por Casteigts et al. para definir algoritmos distribuídos em redes dinâmicas, que utiliza grafos evolutivos para representar a topologia da rede e renomeação de rótulos para expressar a comunicação entre os nós. Utilizamos esta abordagem para estudar o problema da exclusão mútua distribuída em redes dinâmicas e diversos algoritmos propostos para ele, a fim de definir e validar suas condições necessárias e suficientes de conectividade em redes dinâmicas.

Além da formalização de algoritmos, o modelo de grafos evolutivos também pode ser utilizado para analisar redes dinâmicas. Rastros de redes dinâmicas reais são amplamente utilizados na literatura para estudos de algoritmos pois estes geram resultados mais realísticos do que redes simuladas com padrões de movimento. A partir dos detalhes de cada conexão entre nós de um destes rastros, é possível construir um grafo evolutivo, do qual se pode extrair dados como jornadas ótimas entre nós, variação da conectividade no tempo, estabilidade, e periodicidade. Com as informações mencionadas, um pesquisador pode observar com maior precisão as características do rastro, o que facilita na escolha da rede mais apropriada para sua necessidade. Além disso, o conhecimento prévio de tais características de uma rede auxilia no estudo do comportamento de algoritmos executados sobre ela e provém uma validação para suposições geralmente feitas pelos pesquisadores. Para fornecer estas informações, desenvolvemos uma ferramenta Web que analisa rastros de redes dinâmicas e agrega os dados em um formato de fácil visualização. Descrevemos, neste trabalho, a implementação e a utilidade de todos os serviços da ferramenta.

Palavras-chave: DTNs, MANETs, Redes Dinâmicas, Algoritmos Distribuídos, Grafos Evolutivos, Exclusão Mútua Distribuída, Rastros. 


\section{Abstract}

\section{Evolving Graphs in the Modeling and Analysis of Dynamic Networks}

Lately, several networks with dynamic properties (for instance MANETs, DTNs, opportunistic networks, etc) are functioning. In this work, we studied a model for these networks called Evolving Graphs, which allows the expression of the dynamicity of the conections between nodes through a simple extension of the common graph structure. This model is used by the framework proposed by Casteigts et al. to define distributed algorithms in dynamic networks, which uses evolving graphs to represent the network topology and graph relabelling to express the communication between nodes. Using this approach, we study the distributed mutual exclusion problem in dynamic networks and several algorithms proposed to solve it, in order to define and validate their necessary and sufficient connectivity conditions.

Apart from the formalization of algorithms, the evolving graphs model can also be used to analyze dynamic networks. Dynamic network traces are widely used in the literature in order to study algorithms, as they generate better results than simulated networks with movement patterns. From the details of every connection between nodes in a trace, it is possible to build an evolving graph, from which a large amount of information can be extracted, such as optimal journeys between nodes, variation of the conectivity over time, stability and periodicity. With the aforementioned information, a researcher might observe the characteristics of a trace more precisely, which facilitates the process of choosing the most appropriate trace for his needs. Furthermore, the early knowledge of such characteristics of a network helps in the study of the behavior of the algorithms exected over it and provides a validation for the assumptions usually made by the researchers. In order to provide this information, we developed a web tool which analyzes dynamic network traces and aggregates the data in an easily readable format. In this work, we describe the implementation and usefulness of every service in the tool.

Keywords: DTNs, MANETs, Dynamic Networks, Distributed Algorithms, Evolving Graphs, Distributed Mutual Exclusion, Traces. 


\section{Sumário}

$\begin{array}{ll}\text { Lista de Abreviaturas } & \text { ix }\end{array}$

Lista de Símbolos

Lista de Figuras $\quad$ xiii

1 Introdução $\quad 1$

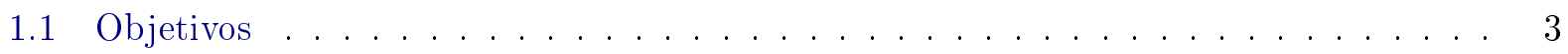

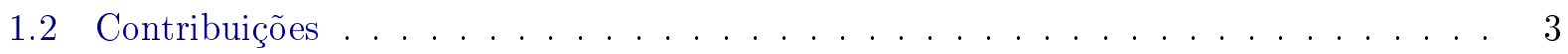

1.3 Organização do Trabalho . . . . . . . . . . . . . . . . . . . . . . . 4

2 Revisão Bibliográfica $\quad 5$

2.1 Modelos para Redes Dinâmicas . . . . . . . . . . . . . . . . . . 5

2.2 Algoritmos Distribuídos . . . . . . . . . . . . . . . . . . . . 6

2.3 Simulação de Redes Dinâmicas e Rastros . . . . . . . . . . . . . . . . . . . 7

3 Conceitos de Grafos Evolutivos e Redes Dinâmicas 9

3.1 Grafos Evolutivos . . . . . . . . . . . . . . . . . . . 9

3.2 Arcabouço para Formalização de Algoritmos Distribuídos . . . . . . . . . . . . . 11

4 Algoritmos para o Problema da Exclusão Mútua Distribuída 15

4.1 Algoritmo de Ricart e Agrawala . . . . . . . . . . . . . . . . . . . . 15

4.1.1 Formalização - Conexões Diretas . . . . . . . . . . . . . . . . . . . . 16

4.1 .2 Formalização - Caminhos Dinâmicos . . . . . . . . . . . . . . . . . 19

4.1.3 Requisitos Computacionais . . . . . . . . . . . . . . . . . . . . 24

4.2 Algoritmo de Helary et al. . . . . . . . . . . . . . . . . . . . . . 24

4.2 .1 Formalização . . . . . . . . . . . . . . . . . . . . 25

4.3 Estendendo o Problema: $K$-Exclusão Mútua $\ldots \ldots \ldots \ldots$

4.3 .1 Formalização . . . . . . . . . . . . . . . . . . . . . . . . 31

4.3 .2 Condição Necessária . . . . . . . . . . . . . . . . . . . . . . 32

4.3 .3 Condição Suficiente . . . . . . . . . . . . . . . . . . . . . . . 32

4.3 .4 Requisitos Computacionais . . . . . . . . . . . . . . . 33

5 Ferramenta para Análise de Rastros $\quad 35$

5.1 Motivação . . . . . . . . . . . . . . . . . . . . . . 35

5.2 Implementação da Ferramenta DTNTES . . . . . . . . . . . . . . . . . . 36 
5.2 .1 Serviços de Conectividade . . . . . . . . . . . . . . . . . . 37

5.2 .2 Serviços de Jornadas . . . . . . . . . . . . . . . . . . . . . . . . . . . . . . . . . . . . . . . . . . 4

5.2 .3 Periodicidade . . . . . . . . . . . . . . . . . . . . 42

5.3 Estudo de Caso: DieselNet . . . . . . . . . . . . . . . . . . . 42

6 Conclusões $\quad 47$

Referências Bibliográficas $\quad 49$ 


\title{
Lista de Abreviaturas
}

\author{
DTN Rede tolerante a atrasos e desconexões (Delay and Disruption Tolerant Network) \\ MANET Rede móvel Ad-hoc (Mobile Ad-Hoc Network) \\ EG Grafo Evolutivo (Evolving Graph) \\ DTNTES Sistema avaliador de rastros de DTNs (DTN Trace Evaluator System)
}




\title{
Lista de Símbolos
}

\author{
$\mathcal{G} \quad$ Grafo Evolutivo \\ $G_{i} \quad$ Grafo que representa a rede no instante de tempo $i$ \\ $u, v \quad$ Nós de um grafo \\ $(u, v) \quad$ Aresta entre os nós $u$ e $v$ \\ $V(\mathcal{G}) \quad$ Conjunto de vértices do grafo evolutivo $\mathcal{G}$ \\ $E\left(G_{i}\right)$ Conjunto de arestas do grafo $G_{i}$ \\ $\mathcal{J} \quad$ Jornada \\ $\mathcal{J}_{u, v} \quad$ Jornada entre os nós $u$ e $v$ \\ $\mathcal{J}_{u, v, t} \quad$ Jornada entre os nós $u$ e $v$, com instante de partida maior que $t$ \\ $\Sigma \quad$ Alfabeto \\ $\lambda_{i}(u) \quad$ Rótulo do nó $u$ no instante $i$ \\ $\mathcal{I} \quad$ Conjunto de estados iniciais de um algoritmo \\ $Z \quad$ Conjunto de regras de renomeação de um algoritmo \\ $\mathcal{A} \quad$ Algoritmo \\ $\mathcal{A}_{i} \quad$ Sequência de renomeações induzida pelo algoritmo $\mathcal{A}$ no instante $i$ \\ $\mathcal{O}_{\mathcal{A}} \quad$ Objetivo do algoritmo $\mathcal{A}$ \\ $C$ Condição de conectividade
}




\section{Lista de Figuras}

1.1 Conexões e Grafo Evolutivo correspondente . . . . . . . . . . . . . . . . . . . 2

3.1 Representação gráfica do grafo evolutivo $\mathcal{G}=\left(G_{0}, G_{1}, G_{2}, G_{3}\right) \ldots \ldots \ldots \ldots$

3.2 Um exemplo de jornadas. . . . . . . . . . . . . . . . . . . . . 11

3.3 Um exemplo da execução de regras monádicas e de comunicação em um contexto de eleição de líder. . . . . . . . . . . . . . . . . . . . . . . . . . . . . . 12

4.1 Um exemplo de sincronização de uma componente. . . . . . . . . . . . . . . . . . 19

4.2 Simulação do algoritmo de Ricart e Agrawala com três nós. . . . . . . . . . . . . . . 22

4.3 Simulação do algoritmo de Helary et al. com três nós. . . . . . . . . . . . . . . . 27

5.1 Tela inicial do sistema DTNTES. . . . . . . . . . . . . . . . 37

5.2 Exemplo de gráfico de conectividade direta na ferramenta DTNTES. . . . . . . . . . 38

5.3 Exemplo de gráfico de conectividade por jornadas na ferramenta DTNTES. . . . . . 39

5.4 Exemplo de gráfico de conexões ativas ao longo do tempo na ferramenta DTNTES. 39

5.5 Exemplo de gráfico de conexões por jornadas ao longo do tempo na ferramenta DT-

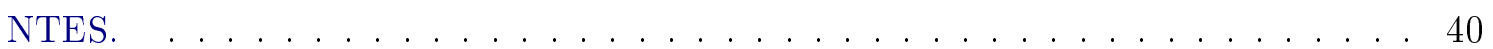

5.6 Exemplo de gráfico de estabilidade na ferramenta DTNTES. . . . . . . . . . . . 40

5.7 Exemplo da tela de visualização de jornadas na ferramenta DTNTES. . . . . . . . . 41

5.8 Gráfico de número de nós por intervalo de porcentagem de conectividade direta. . . 44

5.9 Gráfico de número de nós por intervalo de porcentagem de conectividade por jornadas. . . . . . . . . . . . . . . . . . . . . . 44

5.10 Gráfico de número de conexões diretas ativas por instante de tempo. . . . . . . . . . 44

5.11 Gráfico de número de conexões diretas ativas por instante de tempo. . . . . . . . . . 45

5.12 Gráfico de estabilidade. . . . . . . . . . . . . . . . . . . . . . 46 


\section{Capítulo 1}

\section{Introdução}

Nos dias de hoje, diversas redes com características dinâmicas estão em funcionamento. Chamamos de rede dinâmica qualquer rede que sofre variações em sua topologia ao longo do tempo. Estas variações podem ocorrer devido à mobilidade de nós (que provoca desconexões devido ao alcance limitado da conexão sem fio), falhas, desligamento como forma de economia de energia, entre outras. Esta dinamicidade impossibilita o uso de protocolos comuns de comunicação, como o TCP/IP, visto que a topologia da rede sofre muitas variações e os nós não estão sempre conectados por um caminho. O caminho pode existir ao longo do tempo.

Redes deste tipo possuem muitas utilidades. Uma delas é monitorar condições climáticas e do oceano [ASSC02], pois os sensores comunicam-se entre eles através de uma conexão sem fio e possuem energia muito limitada, então não podem estar conectados o tempo todo. Outro uso comum é em redes veiculares [ESE06], em que carros transmitem dados sobre as rodovias e o tráfego para outros carros e para torres de controle, além de receberem atualizações destes dados. Outro cenário em que redes dinâmicas aparecem é como forma de levar conexão com a internet a localizações remotas [n4c]. Neste caso, um helicóptero, ônibus ou outro tipo de veículo recebe os pedidos dos moradores, os carrega até o ponto de acesso mais próximo, onde os pedidos são enviados e processados, e as respostas são levadas de volta aos moradores.

Como, devido à mobilidade dos nós e às constantes desconexões, a topologia de redes dinâmicas não pode ser representada por meio de grafos estáticos, os caminhos nestas redes não podem ser estabelecidos a priori. De fato, o caminho entre dois nós deve ser construído salto a salto, aproveitando-se de conexões oportunas que aparecem ao longo do tempo e, em geral, não podem ser previstas. Devido às características dinâmicas e de tempo real, que incluem a falta de visão global de cada nó e a não previsibilidade das conexões futuras, a grande maioria dos trabalhos sobre este assunto preocupa-se em descobrir estratégias para contornar estas dificuldades, trabalhando apenas com o conhecimento limitado existente. Poucos trabalhos têm como objetivo encontrar uma modelagem da rede que permita um estudo formal e teórico dos algoritmos, ao invés de apenas experimental.

Por este motivo, existem poucos modelos para redes dinâmicas, uma vez que cada trabalho utiliza uma estrutura apropriada a suas necessidades. A busca de um modelo que possa ser utilizado como padrão no cenário de redes dinâmicas é um desafio que já está em aberto há algum tempo. Um dos modelos que surgiu como opção para uma visão combinatória formal das redes dinâmicas foi a estrutura de Grafos Evolutivos [Fer02]. Um grafo evolutivo é composto por um conjunto de nós, um conjunto de arestas e cada aresta guarda os intervalos de tempo em que pode ser percorrida. Desta 
forma, é possível modelar mobilidade e desligamento de nós por meio dos períodos de conexão e desconexão de cada aresta. A Figura 1.1(b) mostra um exemplo de Grafo Evolutivo.

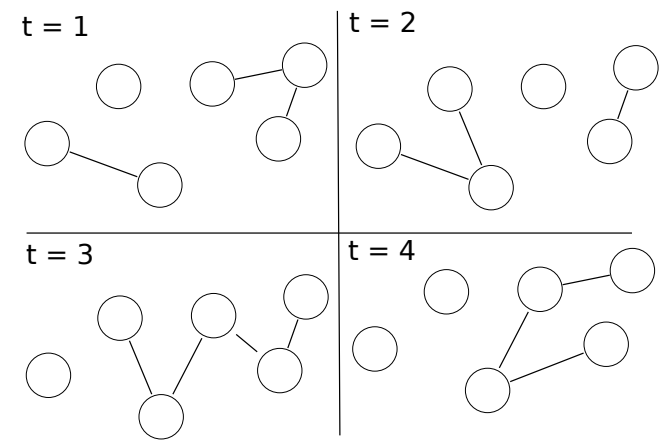

(a) Conexões em quatro instantes de tempo.

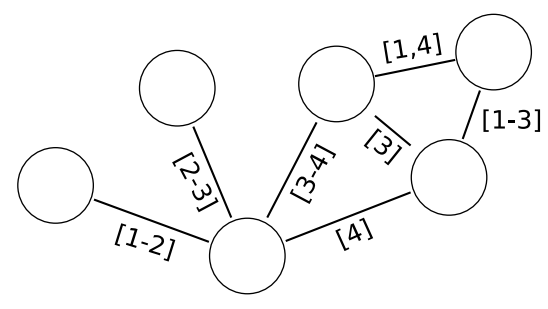

(b) Grafo evolutivo correspondente a 1.1(a)

Figura 1.1: Conexões e Grafo Evolutivo correspondente

Esta estrutura, por ter um formato similar a um grafo comum, herda todas as suas propriedades formais e algorítmicas, que podem ser facilmente adaptadas para a dinamicidade. Deste modo, esta estrutura pode ser utilizada para demonstrar formalmente diversas propriedades de uma rede, bem como definir algoritmos, estudar condições topológicas e extrair informações úteis.

Com o objetivo de desenvolver e formalizar algoritmos distribuídos para redes dinâmicas, Casteigts et al. [CCF10] propuseram um arcabouço que fornece as ferramentas teóricas necessárias para esta tarefa. Este arcabouço permite a caracterização das condições necessárias e/ou suficientes que um algoritmo requer da conectividade da rede, explorando os conceitos de grafos evolutivos e renomeação de rótulos [LS99], uma técnica que permite abstrair a troca de informações entre os nós de forma a não se limitar a um padrão específico de comunicação.

Para demonstrar o potencial dos grafos evolutivos, um estudo sobre este arcabouço teórico foi conduzido e, para tal, foi escolhido um problema muito conhecido e com diversas aplicações na área de algoritmos distribuídos, que é o problema da exclusão mútua. Este problema consiste em, dado um sistema distribuído e um único recurso acessível por todos os nós, garantir que a todo instante deve haver no máximo um nó utilizando o recurso (segurança) e que todo pedido será atendido (vivacidade).

Os algoritmos para exclusão mútua distribuída podem ser divididos em duas classes: permissão e token. Os algoritmos da primeira classe, adotam o princípio de que um nó tem acesso ao recurso compartilhado somente após ter recebido a permissão de todos os outros nós [Lam78, RA81]. Na segunda classe, um token único circula entre os nós e, ao possuí-lo, um nó tem o direito exclusivo de ter acesso ao recurso [SK85, Ray89b, NT96]. A grande maioria destes algoritmos foram definidos para redes estáticas e apenas alguns deles foram adaptados para redes dinâmicas [BVP02, WWV01, BAI94]. Estes trabalhos consideram a rede como um grafo fortemente conexo e, portanto, os algoritmos não funcionam em qualquer tipo de rede dinâmica.

Além da formalização de redes dinâmicas e algoritmos distribuídos, podemos utilizar as propriedades combinatórias dos grafos evolutivos e uma adaptação de resultados clássicos de teoria dos grafos para auxiliar na análise das características de uma rede. Por exemplo, se um determinado algoritmo supõe que a rede deve ser conexa ao longo do tempo, podemos utilizar a estrutura do grafo evolutivo para verificar se esta condição é válida. Da mesma forma, podemos verificar os caminhos 
ótimos entre nós ao longo do tempo, o maior instante de tempo em que a rede é conexa e diversas outras propriedades que podem ser úteis.

Este estudo das características de uma rede dinâmica tem o potencial de auxiliar em diversos trabalhos de pesquisa nesta área. Muitos artigos utilizam rastros de redes dinâmicas para realizar simulações de algoritmos, mas, muito pouca informação sobre os rastros em si estão disponíveis. Algumas características da rede representada pelo rastro, como a conectividade, periodicidade, grau dos nós, entre outras, podem interferir de forma drástica no comportamento de certos algoritmos e o conhecimento destas poderia melhorar a interpretação dos resultados das pesquisas. Uma forma de se extrair estas informações importantes de uma rede é construindo o grafo evolutivo que a representa e executando sobre ele algoritmos que calculem as propriedades desejadas.

Tanto no âmbito teórico, quanto no prático, os grafos evolutivos têm um imenso potencial não explorado. A formalização por meio de grafos evolutivos possui a robustez necessária para o estudo formal do comportamento de algoritmos distribuídos e a riqueza necessária para a extração de informações de redes dinâmicas sem perdas. Acreditamos que o modelo de grafos evolutivos poderia vir a ser utilizado como padrão pelos trabalhos desta área devido a estas qualidades.

\subsection{Objetivos}

O principal objetivo deste trabalho de pesquisa é mostrar o potencial do modelo de grafos evolutivos no estudo das redes dinâmicas. Além desta modelagem ser capaz de exprimir dinamicidade nas conexões de forma simples e baseada na largamente conhecida teoria dos grafos, que empresta toda a carga combinatória e algorítmica para estas redes que anteriormente dependiam apenas de simulações para validação.

Para atingir este objetivo, vamos demonstrar o poder desta modelagem em dois campos distintos: a formalização de algoritmos distribuídos e a extração de informações e análise de redes dinâmicas. Deste modo, mostramos que a estrutura de grafos evolutivos pode ser utilizada tanto para fins teóricos de validação de condições para algoritmos distribuídos quanto para fins práticos de fornecimento de dados sobre redes reais.

\subsection{Contribuições}

Este trabalho apresenta duas contribuições distintas. A primeira contribuição é na parte teórica, em que estudamos a fundo o problema da exclusão mútua distribuída em redes dinâmicas, dois algoritmos que o resolvem e uma generalização deste problema que permite um número fixo de nós na seção crítica a cada instante. A segunda contribuição é uma ferramenta que recebe arquivos de rastros de redes dinâmicas e é capaz de produzir informações úteis sobre esta rede por meio de algoritmos combinatórios. O ponto em comum entre as duas partes do trabalho é que ambas utilizam fortemente a base teórica de grafos evolutivos.

Explorando o arcabouço de Casteigts et al. [CCF10], estudamos as condições necessárias e suficientes que permitem a execução correta em uma rede dinâmica para o algoritmo de permissão de Ricart e Agrawala [RA81], o algoritmo de token de Helary et al. [HPR88] e o algoritmo para $K$ exclusão mútua de Raymond [Ray89a]. O estudo do algoritmo de Ricart e Agrawala é feito em duas etapas, iniciando a partir de um algoritmo baseado diretamente no original, que considera apenas 
conexões diretas entre os nós e, em seguida, mostrando um algoritmo mais sofisticado em que as mensagens são transmitidas por caminhos criados ao longo do tempo. Para os outros algoritmos, mostramos apenas a versão mais adaptada que encontramos para redes dinâmicas. Mostramos, também, que a implementação destes algoritmos é viável em termos computacionais e não apresenta consumo excessivo de tempo ou de espaço.

A ferramenta para análise de rastros de redes dinâmicas foi implementada com o intuito de utilizar a implementação já existente de grafos evolutivos para gerar informações até então não disponíveis sobre os diversos rastros existentes. O sistema DTNTES ${ }^{1}$ oferece dados como as jornadas mais curtas e que chegam mais cedo entre qualquer par de nós, métricas úteis na determinação do tamanho e do volume de conexões da rede, gráficos indicadores da variação da conectividade do grafo ao longo do tempo, do alcance médio dos nós por jornadas e arestas e estimativas do comportamento da rede ao se remover nós.

\subsection{Organização do Trabalho}

Este texto está organizado da seguinte maneira: O Capítulo 2 apresenta uma revisão bibliográfica sobre redes dinâmicas, algoritmos distribuídos e grafos evolutivos; o Capítulo 3 apresenta o modelo de grafos evolutivos e explica o arcabouço utilizado na formalização de algoritmos distribuídos; o Capítulo 4 mostra os algoritmos de exclusão mútua distribuída, sua formalização com base no arcabouço já citado e a definição e demonstração de suas condições necessárias e suficientes para funcionamento em uma rede dinâmica; o Capítulo 5 apresenta a ferramenta DTNTES, discute a motivação para seu desenvolvimento, detalha a implementação e a utilidade de todas as suas funcionalidades e mostra um exemplo de sua utilização sobre um rastro de rede dinâmica real; o Capítulo 6 conclui o trabalho.

\footnotetext{
${ }^{1}$ http://grenoble.ime.usp.br/paulo/dtn/dtntes
} 


\section{Capítulo 2}

\section{Revisão Bibliográfica}

\subsection{Modelos para Redes Dinâmicas}

Diversos modelos foram propostos na literatura para redes dinâmicas. Entre eles, MANETs, redes oportunistas, DTNs e sistemas peer-to-peer [AMMZ10, $\mathrm{MRT}^{+}$05, BBRTP07, $\mathrm{AST}^{+}$10]. Apesar disso, a maioria dos trabalhos que abordam este tipo de rede acaba criando uma modelagem própria, que se adequa melhor ao estudo realizado. Nestes trabalhos, o objetivo principal é abordar problemas conhecidos ante as dificuldades impostas pela dinamicidade da rede, como, por exemplo, a variação constante na topologia, os caminhos construídos ao longo do tempo entre dois nós, a falta de visão global que um nó tem da rede, possíveis falhas nos nós e nas conexões, entre outras.

Um problema importante nas redes dinâmicas, por aplicar-se a muitas situações reais é o da disseminação de informações, que consiste em garantir que uma certa mensagem chegue em todos os nós da rede. Este problema inspirou muitos autores a criarem novas representações para as redes, de forma a facilitar a criação de algoritmos, como o modelo markoviano [BCF09, $\mathrm{CMM}^{+}$08, CMPS09] e o modelo de comunicações oportunistas [AMMZ10].

Uma outra abordagem interessante que auxilia nos estudos de redes em geral (não apenas de computadores, mas sociais, biológicas, etc) é a teoria das redes complexas [ $\left.\mathrm{LFM}^{+} 10\right]$. Esta ferramenta não tem como objetivo modelar as conexões de uma rede em si, mas sim estudar sua topologia, buscando propriedades como small world e scale free, que permitem caracterizar grafos de grande escala (com centenas a milhões e até mesmo bilhões de vértices). As possibilidades abertas pelo uso de redes complexas incluem métricas indicadoras do tamanho da rede, técnicas de criação de grafos aleatórios com características desejadas e técnicas de caracterização de um grafo em busca de certas propriedades. Este estudo baseia-se em análises estatísticas de propriedades das redes, ao invés de características individuais dos vértices e arestas.

O modelo de grafos evolutivos que estudamos foi inicialmente proposto por Ferreira [Fer02]. Em seu trabalho, o modelo é introduzido como uma forma de representar a variação de um grafo ao longo do tempo, diferentemente dos modelos de grafos dinâmicos propostos anteriormente [DFMSN01], que não representavam a dinamicidade diretamente, mas visavam manter as propriedades do grafo quando um nó ou aresta era removido.

A construção deste modelo levou a diversas novas questões teóricas e algorítmicas, estudadas posteriormente. Surgiram, então, novos conceitos sobre a estrutura de grafos evolutivos. Dentre eles, o conceito de jornadas, conectividade ao longo do tempo e árvores evolutivas, extensões de ideias básicas da teoria dos grafos para a dinamicidade das conexões. Estes conceitos representam, 
respectivamente, os caminhos entre dois nós ao longo do tempo, a noção de componentes conexas em um ambiente dinâmico e uma estrutura mínima que representa a existência de jornadas de um nó para todos os outros. Todos estes conceitos foram introduzindos por Ferreira [Fer04].

As jornadas entre nós são o conceito mais importante em um grafo evolutivo e, portanto, o mais estudado. Algoritmos para cálculo de jornadas ótima foram descritos por Xuan et al. [BXFJ02]. Neste trabalho, são mostrados três tipos de parâmetros otimizados: o tempo de chegada, o número de arestas utilizadas e o tempo em trânsito. Estudos sobre as relações entre estes parâmetros foram apresentados por Goldman et al. [GFM10], mostrando que valores ótimos em um destes parâmetros podem gerar valores ruins nos outros e sugerindo a ideia de otimizar mais de um parâmetro simultaneamente.

\subsection{Algoritmos Distribuídos}

A literatura sobre sistemas distribuídos é muito extensa, com inúmeros problemas e soluções diferentes e novos estudos surgindo a cada dia. A maior parte dos trabalhos trata apenas de sistemas estáticos, não considerando nenhum tipo de dinamicidade, pois esta abordagem é largamente utilizada em grades computacionais. Existem muitos problemas distribuídos bastante conhecidos, que podem ser considerados tanto em ambientes dinâmicos, quando em estáticos. Dentre os problemas mais comuns estão a eleição de líder, a deteç̧ão de falhas, a ordenação de eventos, a exclusão mútua e os generais bizantinos.

Escolhemos, para esta trabalho, tratar o problema da exclusão mútua distribuída em redes dinâmicas. Algoritmos para este problema foram propostos em alguns trabalhos anteriormente, especialmente voltados para o modelo de MANETs (Mobile Ad-hoc Networks) [BVP02, WWV01, BAI94]. Entretanto, estes algoritmos consideram a rede como um grafo fortemente conexo, o que é uma suposição muito forte quando se trata de uma rede dinâmica. O objetivo destes trabalhos é apenas adaptar algoritmos de exclusão mútua já existentes no contexto estático para a dinamicidade das redes, fazendo as suposições necessárias. Em nossa pesquisa, adaptamos a definição dos algoritmos e a forma com que os nós se comunicam para tentar obter condições de conectividade menos restritivas, além de demonstrar que tais condições são necessárias e/ou suficientes para a execução correta.

A descrição de um algoritmo distribuído depende fortemente da forma com que os nós se comunicam. Existem diversos modelos de comunicação utilizados na literatura, como passagem de mensagens, memória compartilhada e caixas de correio. Porém, ao definir um algoritmo utilizando um deles, os resultados obtidos são limitados a este modelo. Com o objetivo de criar uma abstração que permitisse definir algoritmos em um nível mais alto, que independa do modelo de comunicação, foi criada uma ferramenta teórica chamada de renomeação de rótulos (graph relabellings) [LS99]. Baseada em computações locais esta ferramenta permite que um algoritmo seja descrito por um conjunto de regras de interações locais, eliminando a dependência entre o algoritmo e o modelo de comunicação. Esta técnica foi inicialmente proposta apenas para redes estáticas, mas pôde facilmente ser adaptada para a dinamicidade no trabalho de Casteigts et al.[CCF10].

Usando modelo de grafos evolutivos para representação da dinamicidade e a técnica de renomeação de rótulos para descrição de algoritmos distribuídos, Casteigts et al. [CCF10] propuseram um arcabouço teórico para a formalização de algoritmos. Além da própria descrição do algoritmo, esta 
ferramenta facilita a definição e a demonstração das condições topológicas necessárias e suficientes para que este funcione corretamente em uma rede dinâmica. Nosso estudo do problema da exclusão mútua distribuída utiliza todas as ferramentas deste arcabouço, apresenta uma sequência de passos para abordar um problema e uma forma de representar disseminação de informações.

\subsection{Simulação de Redes Dinâmicas e Rastros}

A simulação de ambientes de redes que utilizam contatos oportunistas é extremamente importante no estudo de algoritmos sobre redes dinâmicas. Um dos simuladores mais utilizados na literatura é o ONE [KOK09] (Opportunistic Network Environment Simulator), que se destaca por sua simplicidade de uso e extensão, que facilita a adição de novos algoritmos e permite tanto simulação por padrões de movimento quanto a leitura de um rastro de rede real.

O trabalho de Monteiro et al.[MGF07] introduz a utilização de jornadas sobre grafos evolutivos para avaliar protocolos de roteamento em redes dinâmicas simuladas. Mais recentemente, os trabalhos de Goldman et al. [GFM10, GFMF10] mostraram simulações comparando os protocolos de roteamento mais comuns com as três possíveis jornadas ótimas geradas por meio do grafo evolutivo que representa a rede. Estes trabalhos foram os pioneiros na utilização desta estrutura para geração de dados sobre redes dinâmicas por meio de simulações.

Rastros de redes dinâmicas são uma alternativa melhor às redes simuladas, pois seus resultados ficam mais próximos da realidade, uma vez que modelos de movimento aleatório geram redes com características muito diferentes dos cenários reais, causando efeitos indesejados nos algoritmos [BHM07]. Estes rastros estão disponíveis ao público por meio de repositórios de algumas unversidades [cra, uma], como Dartmouth, Massachusetts, entre outras. Estes repositórios guardam também artigos de autores que utilizaram seus dados.

Por exemplo, um trabalho $\left[\mathrm{SMM}^{+} 11\right]$ propõe um sistema de previsão da próxima localização de um usuário a partir do sinal de GPS de seu smartphone e dos sinais de redes Wi-Fi próximas. Para validar seu programa, os autores utilizaram diversos rastros reais, incluindo um com dados de conexão $W i-F i$ do campus de Dartmouth, que se encaixa perfeitamente às necessidades dos autores. Outro trabalho que utiliza um rastro de Dartmouth [SMSC11] estuda entrega de pacotes em redes baseadas em contato humano. Este trabalho valida seu estudo com um arquivo que contém informações sobre encontro de pessoas no campus, o que é bem parecido com a abordagem utilizada por nós.

Um dos conjuntos de rastros hospedados nesta página é o DieselNet [BLV08], uma rede veicular montada no campus de Massachusetts composta por diversos ônibus com a capacidade de se comunicar entre si e com pontos de acesso $W i-f i$ externos. Este rastro foi utilizado em pesquisas de protocolos de roteamento [BGJL06] como forma de substituir os modelos de movimentação simulados, a fim de produzir melhores resultados. 


\section{Capítulo 3}

\section{Conceitos de Grafos Evolutivos e Redes Dinâmicas}

Neste capítulo, apresentaremos uma modelagem para representar uma rede dinâmica e sua dinamicidade de forma adequada às necessidades propostas. Consideramos um sistema distribuído como sendo um conjunto de nós, com um processo por nó, logo, estes nomes serão utilizados como sinônimos ao longo do texto. Os nós são móveis e comunicam-se através de canais sem fio confiáveis, porém, com raio de transmissão limitado. A topologia da rede é dinâmica.

Assumimos que o número $N$ de nós da rede é fixo, conhecido por todos os nós e que não há falhas, nem desligamento. Toda vez que a rede é inicializada com um algoritmo, assumimos que ela executa por tempo infinito (ou seja, redes que são representadas por uma sequência infinita de grafos). Além disso, assumimos também que cada nó $v$ tem um identificador único $i d(v)$ e conhece os identificadores de todos os outros nós. Além disso, consideramos que todo nó possui um relógio lógico [Lam78].

\subsection{Grafos Evolutivos}

Modelaremos a dinamicidade das redes por meio de um grafo evolutivo [Fer04] $\mathcal{G}=\left(G_{0}, G_{1}, \ldots, G_{T}\right)$, em que $T$ é um número natural e $G_{i}=\left(V(\mathcal{G}), E\left(G_{i}\right)\right.$ ) é um grafo com conjunto de nós $V(\mathcal{G})$ (comum a todos os $G_{i}$ ) e conjunto de arestas $E\left(G_{i}\right)$, para todo $i$ entre 0 e $T$. O número $T$ representa o maior instante de tempo em que a rede está modelada. Dizemos que um instante de tempo $t$ está no alcance de $\mathcal{G}$ se $0 \leq t \leq T$. Para representar uma rede até o infinito, simplesmente dizemos que $T=\infty$ e, neste caso, todo número natural é um instante de tempo no alcance de $\mathcal{G}$. Dizemos que $G_{i}$ é o grafo que modela a rede no instante $i$. Desta forma, a mobilidade dos nós e dinamicidade das conexões é completamente modelada, pois se dois nós $u$ e $v$ estão em distância de comunicação no instante $i$, existe uma aresta $(u, v)$ em $E\left(G_{i}\right)$. Neste caso, dizemos que $u$ e $v$ são vizinhos no instante $i$. Note que estamos considerando que as arestas não são dirigidas, ou seja, se $u$ comunica-se com $v$, então $v$ também comunica-se com $u$. Um exemplo de grafo evolutivo pode ser encontrado na Figura 3.1 .

Um conceito importante é a jornada entre dois nós $u$ e $v\left(\mathcal{J}_{u, v}\right)$, que representa um caminho ao longo do tempo de $u$ até $v$ no grafo evolutivo $\mathcal{G}$. Definimos uma jornada como $\mathcal{J}=\left(v_{0} \stackrel{t_{1}}{\rightarrow} v_{1} \stackrel{t_{2}}{\rightarrow}\right.$ $\left.v_{2} \ldots v_{r-1} \stackrel{t_{r}}{\rightarrow} v_{r}\right)$, em que $v_{0}, v_{1}, \ldots, v_{r}$ são vértices distintos em $V(\mathcal{G}), t_{1}, t_{2}, \ldots, t_{r}$ são instantes de 


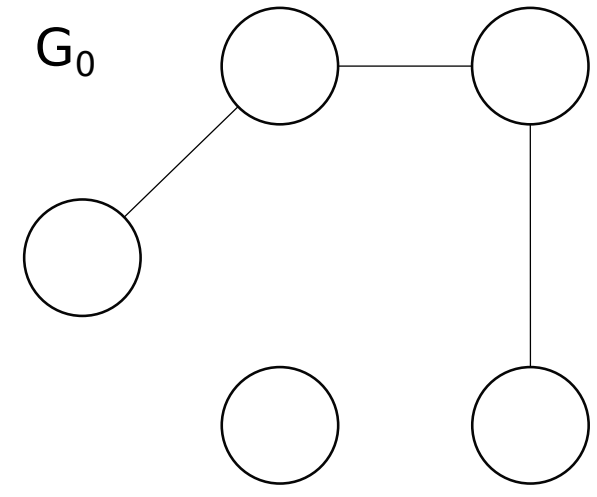

(a)

$\mathrm{G}_{2}$
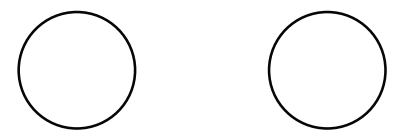

$\square$

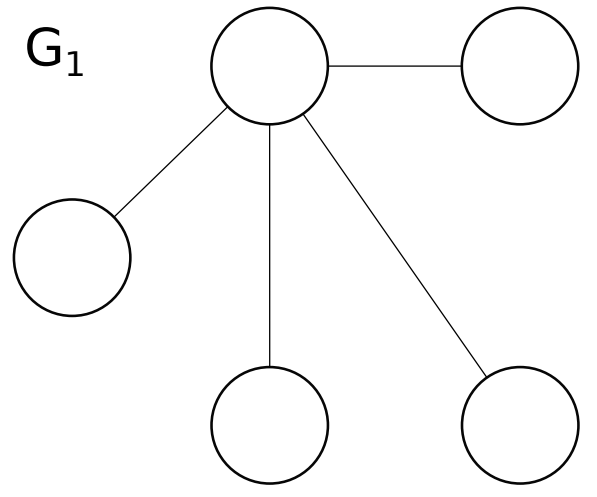

(b)

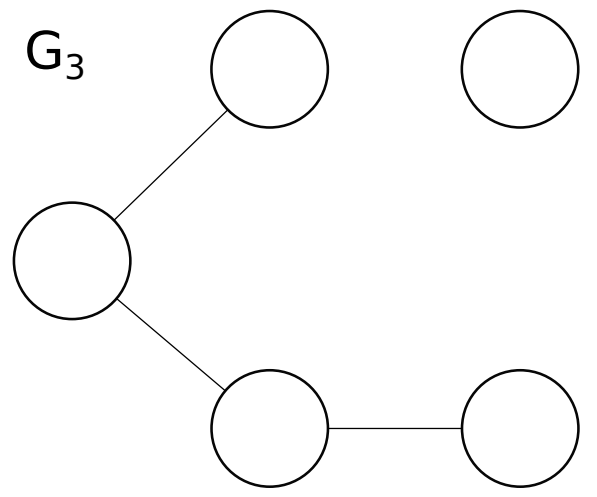

(d)

(c)

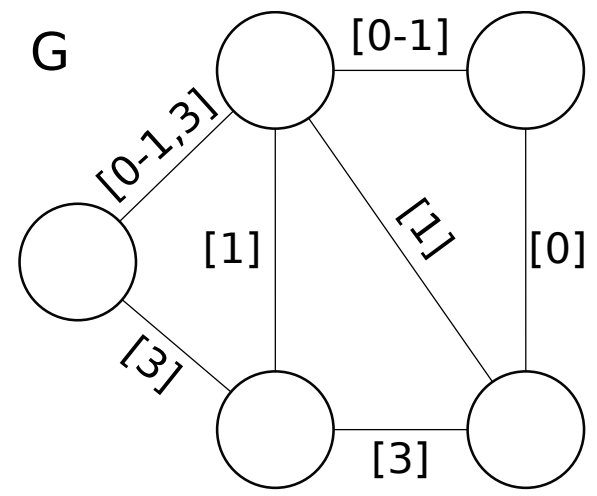

(e)

Figura 3.1: Representação gráfica do grafo evolutivo $\mathcal{G}=\left(G_{0}, G_{1}, G_{2}, G_{3}\right)$. 
tempo no alcance de $\mathcal{G}$ tal que $t_{1} \leq t_{2} \leq \ldots \leq t_{r}$ e $\left(v_{i}, v_{i+1}\right)$ é uma aresta em $E\left(G_{i}\right)$ para todo $i$ entre 0 e $r-1$. Na Figura 3.2 podemos ver um exemplo de jornadas. Neste exemplo, $s \stackrel{2}{\rightarrow} a \stackrel{2}{\rightarrow} b \stackrel{4}{\rightarrow} c \stackrel{6}{\rightarrow} t$ é uma jornada válida, mas $s \stackrel{2}{\rightarrow} a \stackrel{1}{\rightarrow} h \stackrel{0}{\rightarrow} c \stackrel{6}{\rightarrow} t$ não.

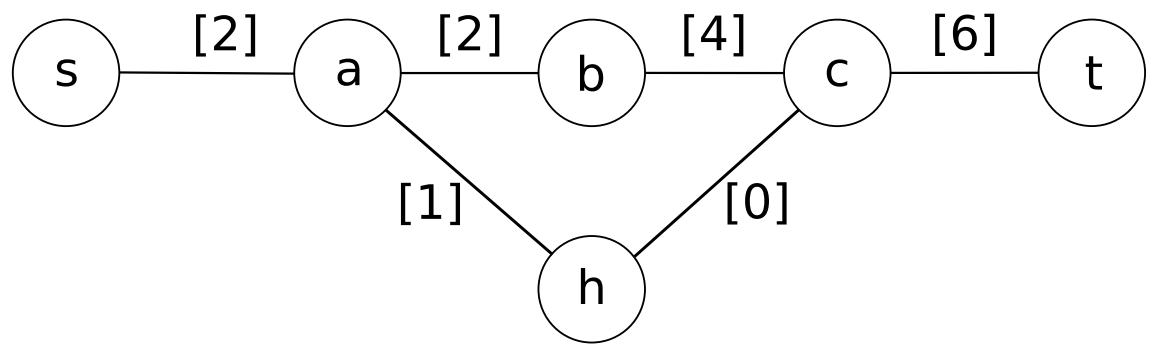

Figura 3.2: Um exemplo de jornadas.

Denotamos por $\mathcal{J}_{u, v, t}$ uma jornada de $u$ para $v$ tal que o instante de percurso da primeira aresta $t_{1}$ é igual a $t$. Se, para dois nós $u, v \in V(\mathcal{G})$ e para todo instante de tempo $t$ no alcance de $\mathcal{G}$, existe um segundo instante $t^{\prime}>t$ tal que existe uma jornada $\mathcal{J}_{u, v, t^{\prime}}$, dizemos que $u$ e $v$ estão conectados a termo.

Podemos definir quatro tipos de jornadas ótimas em um grafo evolutivo, levando em conta medidas distintas para uma jornada $\mathcal{J}_{u, v}$ :

- Chamamos de Foremost Journey a jornada que chega no nó destino no instante mais cedo possível;

- Chamamos de Latest Journey a jornada que sai do nó origem no instante mais tarde possível;

- Chamamos de Shortest Journey a jornada que chega ao destino com o menor número de arcos percorridos;

- Chamamos de Fastest Journey a jornada que chega ao destino permanecendo o menor intervalo de tempo possível em percurso.

Algoritmos para encontrar tais jornadas em um grafo evolutivo foram propostos por Xuan et. al [BXFJ02], exceto pela Latest Journey, que é um trabalho original desenvolvido durante este projeto.

A seção seguinte apresenta um arcabouço que os utiliza na formalização de algoritmos distribuídos e das condições necessárias e suficientes para seu funcionamento.

\subsection{Arcabouço para Formalização de Algoritmos Distribuídos}

Existem diversos modelos de comunicação que podem ser utilizados para expressar algoritmos distribuídos, como, por exemplo, troca de mensagens ou memória compartilhada. Entretanto, ao escrever um algoritmo com um paradigma específico, estamos limitando seu escopo de funcionamento. Com este problema em vista, Casteigts et al. [CCF10] propuseram um arcabouço que utiliza renomeações de rótulo e grafos evolutivos para caracterizar, respectivamente, a comunicação entre os nós e a dinamicidade da topologia da rede.

Neste modelo, os algoritmos distribuídos são descritos a partir de um conjunto de interações locais simples que é independente da maneira com que os nós efetivamente se comunicam. Cada nó 
e aresta possui um estado local, chamado de rótulo, que representa o estado algorítmico da rede e só pode ser alterado por meio de uma interação local, denominada regra de renomeação.

Uma regra de renomeação é composta por pré-condições, que determinam o estado local da rede (referente a rótulos de nós e arestas) necessário para aquela regra, e açôes, que determinam o estado local da rede após a execução da regra. Dividimos as regras de renomeação em regras de comunicação, que dependem de dois ou mais nós, e regras monádicas, executadas em apenas um nó quando seu rótulo corresponde às pré-condições. Portanto, a ação de uma regra de comunicação em um nó só pode ser executada em um certo instante de tempo se este nó estiver conectado a um ou mais nós neste instante (o número e a topologia das conexões necessárias depende das pré-condições da regra), o que não é necessário no caso de uma regra monádica.

A Figura 3.3 ilustra a execução de regras de renomeação em uma rede em um algoritmo de eleição de líder. Em 3.3(a), três nós estão inicialmente ociosos. Em 3.3(b), um dos nós acorda e torna-se um candidato, o que é representado como uma regra monádica. Em 3.3(c) e 3.3(d) o nó candidato se conecta com os outros dois, que ficam derrotados.

$\mathrm{t}=1$
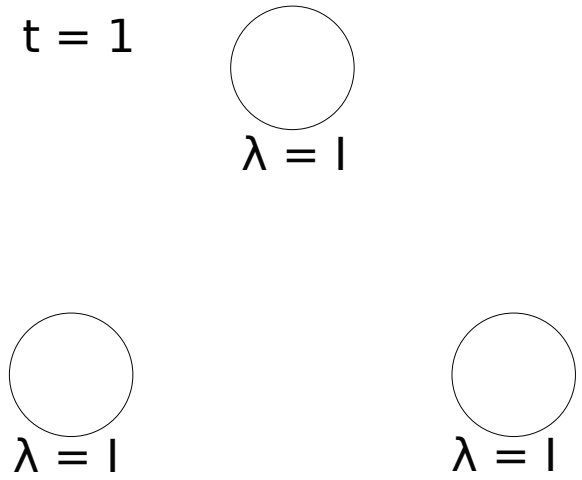

(a)

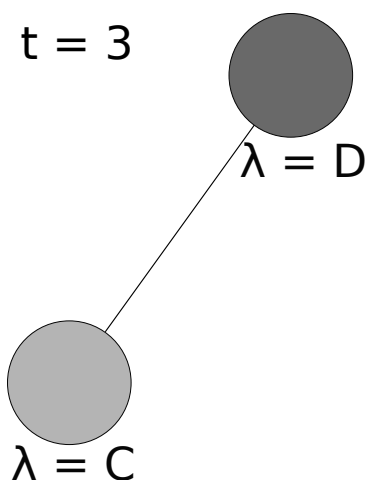

(c)
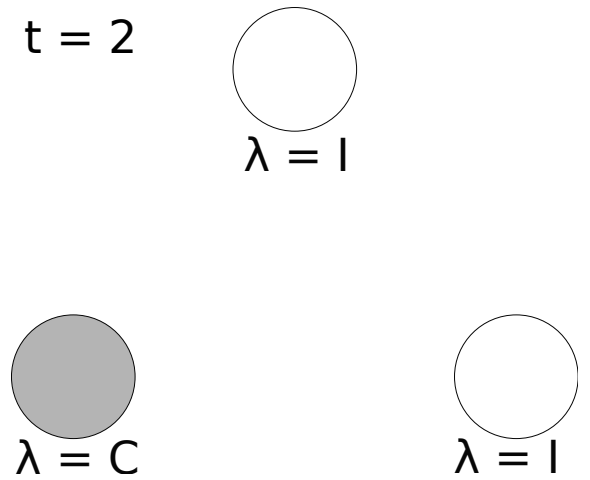

(b)

$t=4$
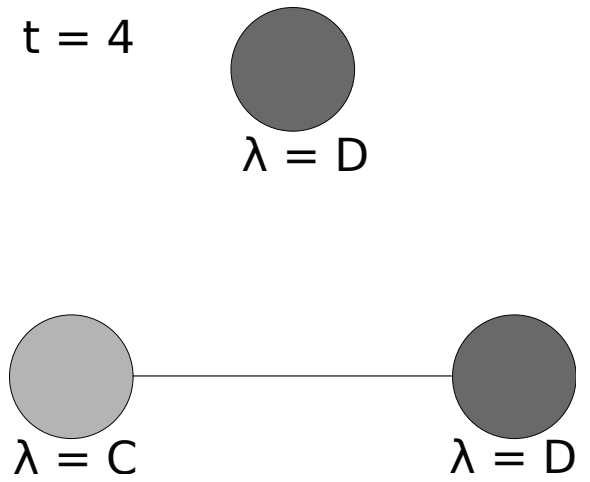

(d)

Figura 3.3: Um exemplo da execução de regras monádicas e de comunicação em um contexto de eleição de líder.

Considere que o sistema é representado pelo grafo evolutivo $\mathcal{G}=\left(G_{0}, G_{1}, \ldots, G_{T}\right)$. No instante de tempo $i$, a rede é representada pelo grafo $G_{i}=\left(V(\mathcal{G}), E\left(G_{i}\right)\right)$. Seja $\Sigma$ um alfabeto e seja $\lambda_{i}: V(\mathcal{G}) \cup E\left(G_{i}\right) \rightarrow \Sigma^{*}$ uma função que associa cada nó e aresta do grafo a uma palavra do alfabeto $\Sigma$, denominada rótulo. Então, no instante $i$, o estado do vértice $v$ de $V(\mathcal{G})$ é representado por $\lambda_{i}(v)$ e o estado da aresta $e$ de $E\left(G_{i}\right)$ é dado por $\lambda_{i}(e)$. O grafo rotulado no instante $i$ é dado pelo par $\left(G_{i}, \lambda_{i}\right)$. Um algoritmo sobre uma rede é representado por uma tripla $(\Sigma, \mathcal{I}, Z)$, em que $\mathcal{I}$ 
é o conjunto de estados iniciais e $Z$ é um conjunto de regras de renomeação.

Num grafo evolutivo, as conexões entre nós são alteradas a cada instante de tempo. Chamamos essas alterações de eventos topológicos e chamaremos de $\mathcal{T}_{i}$ o evento topológico que ocorre entre os instantes de tempo $i-1$ e $i$. Logo, o grafo $G_{i}$ representa a rede logo após o evento $\mathcal{T}_{i}$. Um algoritmo pode realizar diversas regras de renomeação em um dado instante de tempo. Seja $\mathcal{A}$ um algoritmo, chamamos de $\mathcal{A}_{i}$ a sequência de renomeações de rótulo induzida por $\mathcal{A}$ na rede no instante $i$. Se $\left(G_{i}, \lambda_{i}\right)$ é o grafo rotulado no instante $i$ antes de $\mathcal{A}_{i}$, então, chamamos de $\left(G_{i}, \lambda_{i}^{\prime}\right)$ o mesmo grafo após a sequência de renomeações $\mathcal{A}_{i}$. Logo, a sequência de eventos em uma rede dinâmica pode ser vista da seguinte maneira:

$$
\left(G_{0}, \lambda_{0}\right) \stackrel{\mathcal{A}_{0}}{\longrightarrow}\left(G_{0}, \lambda_{0}^{\prime}\right) \stackrel{\mathcal{T}_{1}}{\longrightarrow}\left(G_{1}, \lambda_{1}\right) \stackrel{\mathcal{A}_{1}}{\longrightarrow}\left(G_{1}, \lambda_{1}^{\prime}\right) \stackrel{\mathcal{T}_{2}}{\longrightarrow}\left(G_{2}, \lambda_{2}\right) \ldots
$$

O formalismo acima oferece um meio de representar tanto a dinamicidade da topologia da rede quanto as interações entre nós e mudanças de estado. Portanto, podemos utiliza-lo para buscar as condições necessárias e suficientes referentes à dinâmica da rede para o funcionamento dos algoritmos. Para isto, definimos o objetivo de um algoritmo $\mathcal{O}_{\mathcal{A}}$ como o estado $\mathcal{P}$ da rede que deve ser alcançado ou mantido a partir de um certo instante de tempo. No exemplo anterior, o objetivo do algoritmo de eleição de líder é que exatamente um nó esteja no estado $L$ e todos os outros estejam no estado $D$ (ou seja, que apenas um líder seja eleito). Se um estado deve ser alcançado, o objetivo é que exista um instante de tempo $i$ tal que a propriedade desejada valha em $\left(G_{i}, \lambda_{i}\right)$. Se o estado deve ser mantido em todos os momentos, o objetivo é que, para todo instante de tempo $i$, a propriedade valha em $\left(G_{i}, \lambda_{i}\right)$. Portanto, denotamos:

- $\mathcal{O}_{\mathcal{A}}=\exists i, \mathcal{P}\left(G_{i}, \lambda_{i}\right)$ : quando um estado $\mathcal{P}$ deve ser alcançado;

- $\mathcal{O}_{\mathcal{A}}=\forall i, \mathcal{P}\left(G_{i}, \lambda_{i}\right)$ : quando um estado $\mathcal{P}$ deve ser mantido todo o tempo.

Dizemos que uma condição $C$ (sobre a topologia da rede) é necessária para o algoritmo $\mathcal{A}$ se e somente se para todo grafo evolutivo $\mathcal{G}$, se $C$ não vale em $\mathcal{G}$, então não é possível alcançar o objetivo $\mathcal{O}_{\mathcal{A}}$. Simetricamente, a condição $C$ é suficiente para o algoritmo $\mathcal{A}$ se e somente se para todo grafo evolutivo $\mathcal{G}$, se $C$ vale em $\mathcal{G}$, então o objetivo $\mathcal{O}_{\mathcal{A}}$ sempre será alcançado.

É importante ressaltar que, de acordo com Casteigts et. al [CCF10], a prova de uma condição suficiente só é possível se fizermos alguma suposição que garanta que as regras de renomeação são executadas corretamente.

Nas próximas seções, utilizaremos este arcabouço para tratar do problema da exclusão mútua distribuída em redes dinâmicas. Utilizaremos, para este fim, somente redes que executam por tempo infinito, portanto, todo instante de tempo natural está no alcance da rede. 


\section{Capítulo 4}

\section{Algoritmos para o Problema da Exclusão Mútua Distribuída}

O problema da exclusão mútua distribuída consiste em um conjunto de processos que compartilha um único recurso e, para o qual cada um destes necessita de acesso exclusivo. Quando um nó obtém o recurso, dizemos que eles está na seção crítica. O recurso é conseguido a partir da execução de um segmento de código chamado de seção crítica. Portanto, um algoritmo para exclusão mútua distribuída deve garantir as duas seguintes propriedades:

- Segurança (safety): a todo instante, no máximo um nó está na seção crítica;

- Vivacidade (liveness): um processo que requisita acesso à seção crítica o obtém em tempo finito.

Em geral, algoritmos para exclusão mútua distribuída são divididos em duas classes: baseados em permissão e baseados em token. Diz-se que um algoritmo é baseado em permissão se, para conseguir o recurso, um nó precisa da permissão de todos os outros nós da rede. Analogamente, diz-se que um algoritmo é baseado em token se existe circulando pela rede uma mensagem especial que permite acesso exclusivo à seção crítica ao processo que possuir essa mensagem.

Assim como descrevemos no capítulo 3, consideramos que a rede possui um número fixo de nós, na qual não há desligamento nem falhas e que toda mensagem enviada chegará em seu destino em tempo finito.

\subsection{Algoritmo de Ricart e Agrawala}

Nesta seção, apresentaremos um estudo do algoritmo de Ricart e Agrawala com base no arcabouço de Casteigts et al.

Neste algoritmo, todos os nós inicialmente estão no estado ocioso e, quando precisam entrar na seção crítica, executam o protocolo de entrada. No protocolo de entrada, o nó envia um pedido para cada um dos outros nós no sistema. Neste caso, denotamos que o nó se encontra no estado requisitando. Este nó deve esperar a resposta de cada um dos outros nós antes de executar sua seção crítica e utilizar o recurso. O nó passa então ao estado utilizando.

Todo processo possui um relógio lógico [Lam78] e toda mensagem de requisição é marcada com o tempo do relógio do nó que a enviou. Antes de enviar uma mensagem, o processo incrementa seu 
relógio lógico e, ao receber uma mensagem, o atualiza com o máximo entre o tempo da mensagem recebida e o tempo de seu próprio relógio. Logo, é possível estabelecer uma ordem total entre as requisições, baseada no valor de suas marcas de tempo e, em caso de empate, no identificador único de cada processo. Em outras palavras, uma mensagem de requisição tem prioridade sobre todas as outras cujas marcas de tempo sejam maiores (ou seja, que foram emitidas depois dela). Se as duas mensagens tem marcas de tempo iguais, aquela que foi emitida pelo processo com o menor identificador tem prioridade. Em ambos os casos, dizemos que a mensagem de maior prioridade tem precedência sobre a outra.

Quando um processo recebe um pedido, ele envia sua permissão se não estiver interessado no recurso (isto é, se o processo está no estado ocioso) ou se está requisitando, mas o pedido recebido tem precedência sobre seu próprio; em caso contrário, os pedidos recebidos são respondidos durante a execução do protocolo de saída (após o final da seção crítica). Neste momento, o processo também muda para o estado ocioso.

A prova da correção do algoritmo de Ricart e Agrawala pode ser encontrada em [RA81].

Nas próximas seções, mostraremos duas formalizações para este algoritmo baseadas no arcabouço de Casteigts et al. A primeira, mais simples, considera apenas conexões diretas entre nós. Em seguida, com uma formalização mais sofisticada, mostramos um algoritmo capaz de promover comunicação entre nós que não se conectam diretamente. Em ambos os casos, mostramos as condições necessárias e suficientes para seu funcionamento correto. Para isso, assumimos que a aplicação que roda nos nós executa o algoritmo de exclusão mútua corretamente, ou seja, primeiro executa o protocolo de entrada, depois a seção crítica e, por fim, o protocolo de saída.

\subsubsection{Formalização - Conexões Diretas}

Esta formalização implementa exatamente o algoritmo definido anteriormente, em que os pedidos e respostas só são transmitidos quando os dois nós envolvidos estão diretamente conectados em um dado instante.

- Alfabeto: $I$ (ocioso), $U$ (utilizando), $\left(R, n, t_{l}, A\right)$ (requisitando, seu pedido foi emitido com tempo lógico $t_{l}$, obteve $n$ respostas e guarda todos os nós que já responderam no conjunto $A$ );

- Estados iniciais: todos os nós começam com $I$;

- Objetivo: A meta do algoritmo é garantir as propriedades de segurança e vivacidade. Os objetivos sobre o grafo evolutivo rotulado $(\mathcal{G}, \lambda)$ são:

1. A cada instante de tempo $i$, não existem dois nós $u$ e $v$ em $V(\mathcal{G})$ tal que $\lambda_{i}(u)=\lambda_{i}(v)=U$ (Segurança).

2. A cada instante de tempo $i$ e para todo nó $u$ em $V(\mathcal{G})$, se $\lambda_{i}(u)=\left(R, n, t_{l}, A\right)$, então existe um instante de tempo $j>i$ tal que $\lambda_{j}(u)=U$ (Vivacidade).

- Protocolo de entrada:

1. pré-condição: $\lambda_{i}(v)=I$

ação: $\lambda_{i}(v)=\left(R, 0, t_{l}, \emptyset\right)$

(Um nó ocioso requisita o recurso); 
2. pré-condições: $\lambda_{i}\left(v_{1}\right)=\left(R, N-1, t_{l}, A_{v_{1}}\right)$

ação: $\lambda_{i}\left(v_{1}\right):=U$

(Um nó obtém $N-1$ respostas e pode utilizar o recurso).

- Protocolo de saída:

pré-condição: $\lambda_{i}(v)=U$

ação: $\lambda_{i}(v)=I$

(Um nó que estava utilizando volta a ficar ocioso).

- Regras de Comunicação:

1. pré-condições: $\lambda_{i}\left(v_{1}\right)=\left(R, n, t_{l}, A_{v_{1}}\right) \wedge \lambda_{i}\left(v_{2}\right)=I \wedge v_{2} \notin A_{v_{1}}$ ação: $\lambda_{i}\left(v_{1}\right):=\left(R, n+1, t_{l}, A_{v_{1}} \cup\left\{v_{2}\right\}\right)$

(Um nó que está requisitando o recurso encontra um nó ocioso e obtém uma resposta);

2. pré-condições: $\lambda_{i}\left(v_{1}\right)=\left(R, n, t_{l_{1}}, A_{v_{1}}\right) \wedge \lambda_{i}\left(v_{2}\right)=\left(R, m, t_{l_{2}}, A_{v_{2}}\right) \wedge\left(t_{l_{1}}<t_{l_{2}} \vee\left(t_{l_{1}}=\right.\right.$ $\left.\left.t_{l_{2}} \wedge i d\left(v_{1}\right)>i d\left(v_{2}\right)\right)\right) \wedge v_{2} \notin A_{v_{1}}$ ação: $\lambda_{i}\left(v_{1}\right):=\left(R, n+1, t_{l_{1}}, A_{v_{1}} \cup\left\{v_{2}\right\}\right)$

(Um nó que está requisitando o recurso encontra outro no mesmo estado, mas com menor prioridade, e obtém uma resposta).

Podemos perceber que, no protocolo de saída, um nó não precisa responder aos pedidos pendentes. Isso acontece pois quando este nó encontrar novamente com algum outro que lhe fez um pedido e não foi atendido, este outro nó agora terá prioridade e conseguirá a resposta, uma vez que, mesmo que o primeiro tenha emitido um novo pedido, sua prioridade será menor.

\section{Condição Necessária}

Para estabelecer uma condição necessária para este algoritmo, devemos assumir que pelo menos uma requisição é feita na rede ao longo de sua execução. Perceba que sem esta suposição, em casos em que não há pedidos, qualquer topologia de rede garante que os objetivos do algoritmo serão alcançados. Logo, qualquer condição que digamos ser necessária viola a propriedade mencionada anteriormente que diz que uma condição só é necessária se o algoritmo falha para toda topologia em que não vale esta condição.

Proposição 1. A condição $C_{1}(\mathcal{G})=$ para todo par de vértices u e $v$ em $V(\mathcal{G})$, existe um instante de tempo $i$ tal que a aresta $(u, v)$ está em $E\left(G_{i}\right)$ é uma condição necessária para o algoritmo dado.

Prova: Vamos provar que para todo grafo evolutivo $\mathcal{G}$, se $C_{1}$ não vale em $\mathcal{G}$, então existe um instante de tempo $i$ e um vértice $u$ em $V(\mathcal{G})$ tal que $\lambda_{i}(u)=\left(R, n, t_{l}, A\right)$ e, para todo instante de tempo $j>i, \lambda_{j}(u) \neq U$. Ou seja, provaremos que, se existe algum par de vértices que não se conecta em nenhum momento em uma rede, a vivacidade do algoritmo é violada nesta rede.

Suponha que existe um nó $u$ em $V(\mathcal{G})$ e um instante de tempo $i$ tal que $\lambda_{i}(u)=\left(R, 0, t_{l}, \emptyset\right)$ e suponha que existe um vértice $v$ tal que $(u, v)$ não é uma aresta em $E\left(G_{k}\right)$ para nenhum instante de tempo $k>i$. Como não existe aresta entre $u$ e $v$, estes nós nunca poderão realizar as regras de comunicação, portanto, $u$ nunca receberá uma resposta de $v$ e poderá chegar, no máximo, ao estado 
$\left(R, N-2, t_{l}, V(\mathcal{G}) \backslash\{u, v\}\right)$, ou seja, nunca realizará a segunda regra do protocolo de entrada para passar ao estado $U$. Logo, $u$ nunca conseguirá utilizar o recurso, ou seja, não existe um instante de tempo $j>i$ tal que $\lambda_{j}(u)=U$. Portanto, $C_{1}$ é uma condição necessária para o algoritmo.

\section{Condição Suficiente}

Hipótese: A prova de uma condição suficiente, segundo [CCF10] só é possível se assumirmos alguma hipótese que garanta que as regras de transição são executadas corretamente na rede. Neste caso, assumimos que todo nó consegue realizar pelo menos uma regra de comunicação com cada um de seus vizinhos e uma regra monádica em um dado instante de tempo. Esta hipótese é chamada hipótese da progressão.

Proposição 2. A condição $C_{2}(\mathcal{G})=$ para todo par de vértices u e v em $V(\mathcal{G})$ e para todo instante de tempo $i$, existe um instante $j \geq i$ tal que $(u, v)$ é uma aresta em $E\left(G_{j}\right)$, acrescida da hipótese da progressão é uma condição suficiente para o algoritmo dado.

Prova: 1) Segurança é preservada: Vamos provar que em cada instante de tempo, pode haver no máximo um vértice utilizando o recurso. Suponha que, em um dado momento, existem dois nós $u$ e $v$ em $V(\mathcal{G})$ utilizando o recurso (ou seja, no estado $U$ ). Isso significa que ambos os nós receberam pelo menos $N-1$ respostas, que os permitiu executar a segunda regra do protocolo de entrada. Considere os pedidos enviados por estes dois nós para obter o recurso. Devido a ordem total imposta pelas marcas de tempo dos pedidos e pelos identificadores dos nós, um dos pedidos tem precedência sobre o outro. Suponha que $u$ fez o pedido de menor prioridade. Como $u$ está no estado $U$, isso quer dizer que este nó recebeu $N-1$ respostas, incluindo uma de $v$. Entretanto, o pedido de $v$ tem precedência sobre o de $u$, ou seja, $v$ não pode ter enviado uma resposta para $u$, uma vez que um nó só o faz se está ocioso (primeira regra de comunicação) ou se o pedido recebido tem maior prioridade (segunda regra de comunicação). Portanto, chegamos a uma contradição. Logo, não pode haver mais de um nó no estado $U$ em um dado instante, então, a segurança é garantida.

2) Vivacidade é preservada: Vamos provar que, se a condição $C_{2}$ vale na rede $\mathcal{G}$, então todo nó que realiza o protocolo de entrada, em algum momento consegue acesso ao recurso. Suponha que, num dado instante, existe um conjunto $S_{R} \subseteq V(\mathcal{G})$ de nós requisitando o recurso (no estado $\left.\left(R, n, t_{l}, S\right)\right)$. Devido à condição $C_{2}$, existe uma conexão futura entre cada nó de $S_{R}$ e cada um dos outros nós em $V(\mathcal{G})$. Sabemos também que os pedidos enviados pelos nós em $S_{R}$ são totalmente ordenados. Considere o pedido de maior prioridade segundo esta ordem total. Devido à condição $C_{2}$ e à hipótese da progressão, este nó se conectará com todos os ouros nós da rede. Como este pedido tem a maior prioridade entre os nós em $S_{R}$, ele, a cada conexão, executa a segunda regra de comunicação se o outro nó estiver em $S_{R}$ ou a primeira, se não estiver. A cada conexão, o nó recebe uma resposta. Portanto, este nó receberá $N-1$ respostas, então, será capaz de executar a segunda regra do protocolo de entrada e acessar o recurso. Consequentemente, se, um dado instante, existe um conjunto de nós requisitando o recurso, aquele que tiver a maior prioridade conseguirá, em algum momento, acessá-lo. Além disso, como existe uma ordem total nos pedidos e, após liberar o recurso, o pedido satisfeito deixa de ser o de maior prioridade, os pedidos de cada nó de $S_{R}$ irão, em algum momento, passar a ser o pedido de maior prioridade. Portanto, como cada processo que envia um pedido, em algum momento obtém o recurso, a propriedade da vivacidade é garantida. 


\subsubsection{Formalização - Caminhos Dinâmicos}

A condição suficiente para o algoritmo anterior é bastante restritiva. Se construirmos um algoritmo que utilize caminhos construídos ao longo do tempo, poderemos encontrar uma condição mais fraca.

Para evitar a necessidade de conexões diretas, cada nó deve guardar e encaminhar todas as requisições e respostas que ele receber, mesmo que não sejam para ele. Deste modo, o rótulo de cada nó incluirá os seguintes conjuntos:

- $P$ : conjunto de requisições recebidas cujos elementos tem a estrutura: (processo que requisitou, marca de tempo da requisição);

- $Q$ : conjunto de pedidos recebidos cujos elementos tem a estrutura: (processo que requisitou, processo que respondeu, marca de tempo da requisição).

Estes conjuntos são disseminados de forma epidêmica pela rede: em qualquer instante de tempo $i$, os nós de cada componente conexa de $G_{i}$ (subgrafo de $G_{i}$ no qual qualquer par de vértices está conetado por um caminho) atualiza seus conjuntos, fazendo a união deles. Existem diversas maneiras de implementar esta atualização (por exemplo, cada nó trocar informações com todos os outros nós na componente) mas não vamos detalha-las no algoritmo. Um exemplo de como as componentes são atualizadas pode ser visto na Figura 4.1. Inicialmente, as listas dos nós possuem conteúdos diferentes $(4.1(\mathrm{a}))$, mas, após a sincronização, toda a componente recebe todos os pedidos e respostas (4.1(b)).

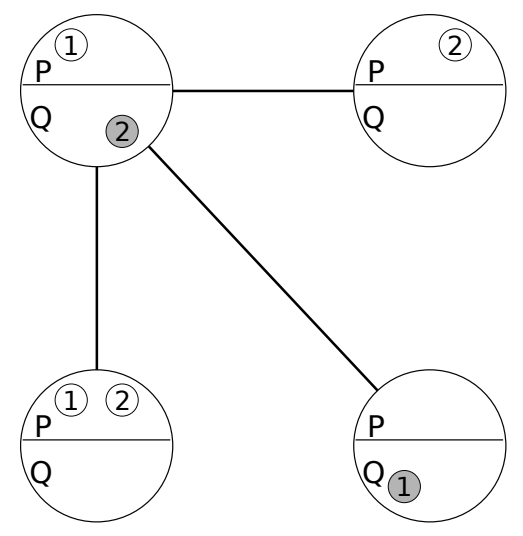

(a)

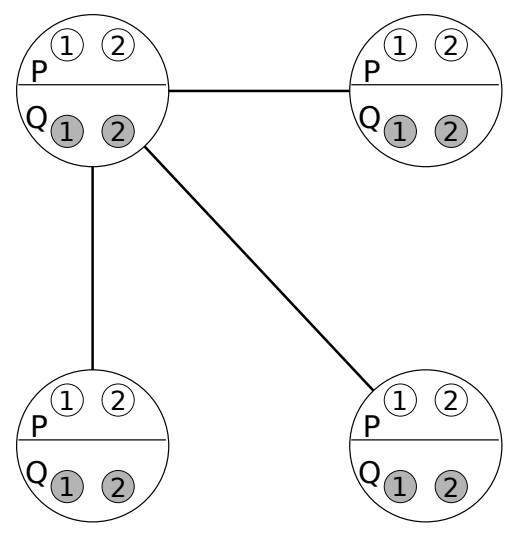

(b)

Figura 4.1: Um exemplo de sincronização de uma componente.

Ao receber uma nova mensagem de requisição, o nó deve decidir se envia ou não uma resposta. Para cada resposta recebida, o processo deve registrar o nó que a enviou para garantir que cada resposta é contada apenas uma vez. Quando o processo termina sua seção crítica, ele executa o protocolo de saída, que consiste em voltar ao estado ocioso e enviar respostas a todas as requisições pendentes.

- Alfabeto: $(I, P, Q)$ (ocioso), $(U, P, Q)$ (utilizando), $\left(R, n, t_{l}, A, P, Q\right)$ (requisitando, o pedido foi enviado com tempo lógico $t_{l}, n$ respostas foram obtidas e todos os nós no conjunto $A$ responderam ao pedido). $P$ e $Q$ são, respectivamente, a lista de pedidos e respostas recebidas, 
como definido anteriormente. Usaremos * para indicar que uma determinada componente do rótulo pode ter qualquer valor válido. Por exemplo, denotamos por $(*, P, Q)$ o rótulo cujo estado pode ser $I, R$ ou $U$. O tamanho das estruturas que compõem um rótulo pode ser ilimitado, mas, como discutido na seção 4.1.3, elas podem ser implementadas de forma a limitar seu tamanho.

- Estado inicial: Todo nó começa no estado $(I, \emptyset, \emptyset)$.

- Objetivo: A meta do algoritmo é garantir as propriedades de segurança e vivacidade. Os objetivos sobre o grafo evolutivo rotulado $(\mathcal{G}, \lambda)$ são:

1. A cada instante de tempo $i$, não existem dois nós $u$ e $v$ em $V(\mathcal{G})$ tal que $\lambda_{i}(u)=\lambda_{i}(v)=U$ (Segurança).

2. A cada instante de tempo $i$ e para todo nó $u$ em $V(\mathcal{G})$, se $\lambda_{i}(u)=\left(R, n, t_{l}, A\right)$, então existe um instante de tempo $j>i$ tal que $\lambda_{j}(u)=U$ (Vivacidade).

- Protocolo de entrada: (regras monádicas)

1. Pré-condições: $\lambda_{i}(v)=(I, P, Q)$

Ações: $\lambda_{i}(v)=\left(R, 0, t_{l}, \emptyset, P \cup\left\{\left(v, t_{l}\right)\right\}, Q\right)$

( $O$ nó $v$ muda seu estado para $R$ e adiciona seu próprio pedido a $P$ ).

2. Pré-condições: $\lambda_{i}(v)=\left(R, N-1, t_{l}, A, P, Q\right)$

Ações: $\lambda_{i}(v):=(U, P, Q)$

( $O$ nó $v$, que está requisitando, obtém $N-1$ respostas e pode usar o recurso).

- Protocolo de saída: (regra monádica)

Pré-condições: $\lambda_{i}(v)=(U, P, Q)$

Ações: $\lambda_{i}(v)=\left(I, P, Q \cup\left\{\left(p, v, t_{l}\right) \mid\left(p, t_{l}\right) \in P\right\}\right)$

( $O$ nó $v$ muda seu estado para $I$ e registra em $Q$ que enviou respostas para todos os pedidos pendentes).

- Regra de comunicação:

Requisitos topológicos: Uma componente conexa $C \in V\left(\mathcal{G}_{t}\right)$ tal que $\lambda_{i}(u)=\left(*, P_{u}, Q_{u}\right)$ para todo $u \in C$

Ações: Para cada $u \in C, \lambda_{i}(u)=\left(*, \bigcup_{v \in C} P_{v}, \bigcup_{v \in C} Q_{v}\right)$

(Todo nó de toda componente conexa no instante $t$ sincroniza suas listas de pedidos e respostas, não importando em que estado estão).

- Regras monádicas de atualização de conjuntos:

1. Pré-condições: $\lambda_{i}(v)=(I, P, Q) \wedge \exists(p, t) \in P,\left(p, v, t_{l}\right) \notin Q$

Ações: $\lambda_{i}(v):=\left(I, P, Q \cup\left(p, v, t_{l}\right)\right)$

( $O$ nó $v$ está ocioso e tem uma requisição pendente para a qual ainda não enviou resposta).

2. Pré-condições: $\lambda_{i}(v)=\left(R, n, t_{l_{1}}, A, P, Q\right) \wedge \exists\left(p, t_{l_{2}}\right) \in P,\left(p, v, t_{l_{2}}\right) \notin Q \wedge\left(t_{l_{1}}>t_{l_{2}} \vee\left(t_{l_{1}}=\right.\right.$ $\left.\left.t_{l_{2}} \wedge i d(p)<i d(v)\right)\right)$

Ações: $\lambda_{i}(v):=\left(R, n, t_{l_{1}}, A, P, Q \cup\left(p, v, t_{l_{2}}\right)\right)$

(O pedido de $p$ tem precedência sobre o de $v$ e $v$ ainda não enviou resposta para $p$ ). 
3. Pré-condições: $\lambda_{i}(v)=\left(R, n, t_{l}, A, P, Q\right) \wedge \exists p,\left(v, p, t_{l}\right) \in Q \wedge p \notin A$.

Ações: $\lambda_{i}(v):=\left(\left(R, n+1, t_{l}, A \cup\{p\}\right), P, Q\right)$

$(O$ nó $v$ recebeu uma resposta de $p$ para seu pedido; $v$ deve registrar que a resposta de $p$ apenas se esta resposta ainda não foi registrada).

A Figura 4.2 mostra uma simulação da execução do algoritmo. Os tempos lógicos associados aos pedidos foram omitidos para facilitar a compreensão.

- Inicialmente, em 4.2(a) os nós $v_{1}$ e $v_{3}$ pedem o recurso no instante 0 (a cor cinza clara indica o estado $R$ e os círculos pretos menores representam o pedido).

- Em 4.2(b), os nós $v_{1}$ e $v_{2}$ se comunicam, $v_{2}$ recebe o pedido de $v_{1}$ e envia uma resposta (círculo pequeno cinza).

- Em 4.2(c) $v_{2}$ conecta-se com $v_{3}$ e o envia uma resposta. $v_{3}$ também recebe o pedido de $v_{1} \mathrm{e}$ envia sua resposta (círculo pequeno branco), pois o pedido de $v_{1}$ tem precedência sobre o seu.

- Em $4.2(\mathrm{~d}), v_{1}$ recebe a resposta de $v_{3}$ e pode usar o recurso (o estado $U$ é representado pela cor cinza escuro). $v_{1}$ também recebe o pedido de $v_{3}$, mas ainda não o responde.

- Em 4.2(e) $v_{1}$ termina de usar o recurso, volta ao estado ocioso e envia sua resposta a $v_{3}$, que chega em seu destino no mesmo instante. $v_{3}$ agora pode usar o recurso.

- Finalmente, em $4.2(\mathrm{f}), v_{3}$ libera o recurso e todos os nós estão ociosos novamente.

\section{Condição Necessária}

Para estabelecer uma condição necessária para este algoritmo, devemos assumir que pelo menos uma requisição é feita na rede ao longo de sua execução. Perceba que sem esta suposição, em casos em que não há pedidos, qualquer topologia de rede garante que os objetivos do algoritmo serão alcançados. Logo, qualquer condição que digamos ser necessária viola a propriedade mencionada anteriormente que diz que uma condição só é necessária se o algoritmo falha para toda topologia em que não vale esta condição.

Proposição 3. A condição $C_{3}(\mathcal{G})=$ para todo par de vértices u e $v$ em $V(\mathcal{G})$, existe uma jornada $\mathcal{J}_{u, v}$ e uma jornada $\mathcal{J}_{v, u}$ é uma condição necessária para o algoritmo dado.

Prova: Vamos provar que para todo grafo evolutivo $\mathcal{G}$, se $C_{3}$ não vale em $\mathcal{G}$, então existe um instante de tempo $i$ e um vértice $u$ em $V(\mathcal{G})$ tal que $\lambda_{i}(u)=\left(R, n, t_{l}, A, P, Q\right)$ e, para todo instante de tempo $j>i, \lambda_{j}(u) \neq(U, P, Q)$. Ou seja, provaremos que, se existe algum par de vértices tal que não existem jornadas entre estes vértices, a vivacidade do algoritmo é violada nesta rede.

Suponha que existe um nó $u$ em $V(\mathcal{G})$ e um instante de tempo $i$ tal que $\lambda_{i}(u)=\left(R, 0, t_{l}, \emptyset, P, Q\right)$ e seja $v$ um vértice em $V(\mathcal{G})$. Se não existe $J_{u, v}$, por mais que diversas regras de comunicação sejam executadas ao longo da rede, o pedido de $u$ nunca chegará até $v$. Ou seja, não existe uma sequência de nós $\left(v_{1}, v_{2}, \ldots, v_{k}\right)$ de $V(G)$ tal que $u=v_{1}$ e $v=v_{k}$ e uma sequência de instantes de tempo $\left(t_{1}, t_{2}, \ldots, t_{k-1}\right)$ tal que $v_{i}$ está na mesma componente conexa que $v_{i+1}$ no instante $t_{i}$, 


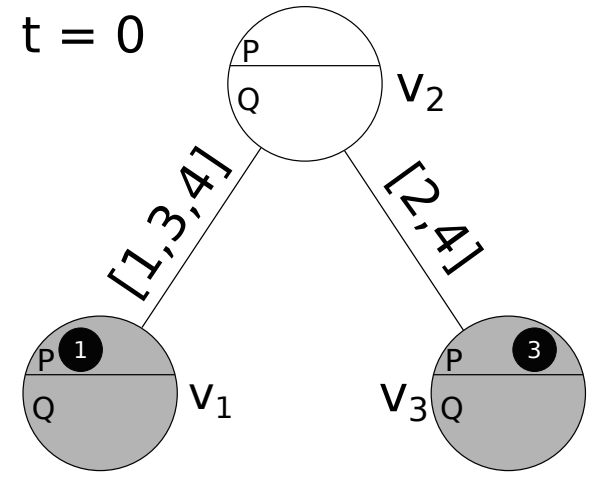

(a)

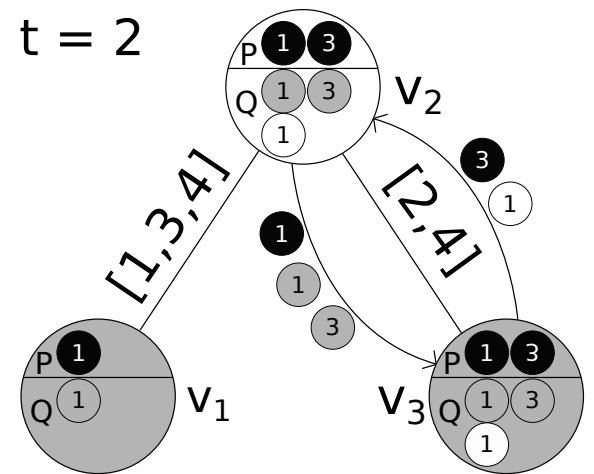

(c)

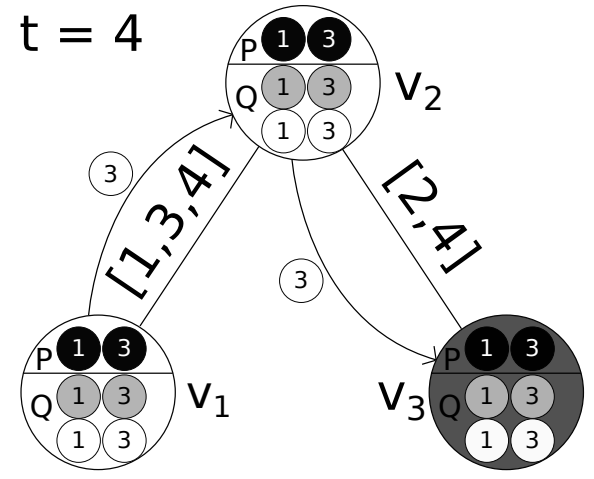

(e)

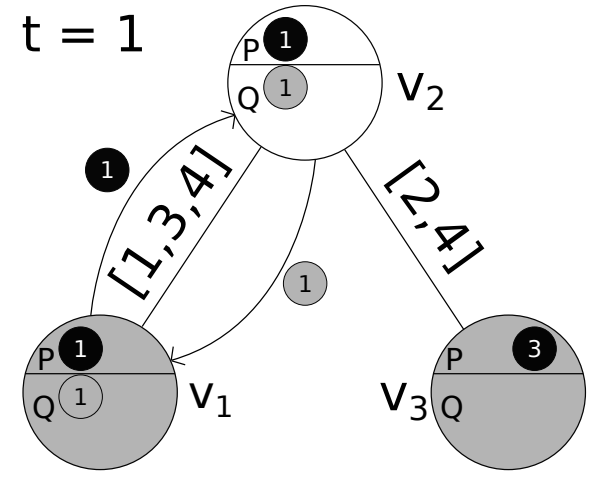

(b)

$\mathrm{t}=3$

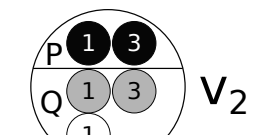

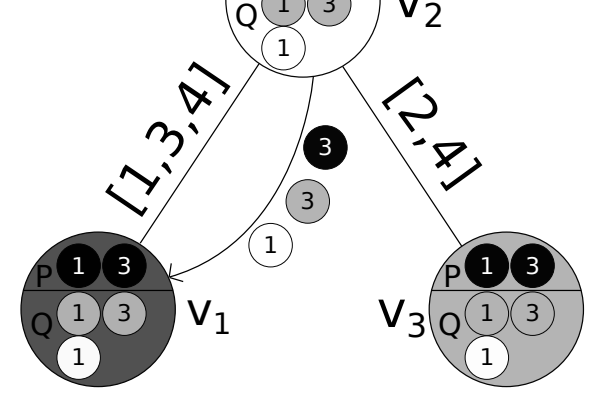

(d)
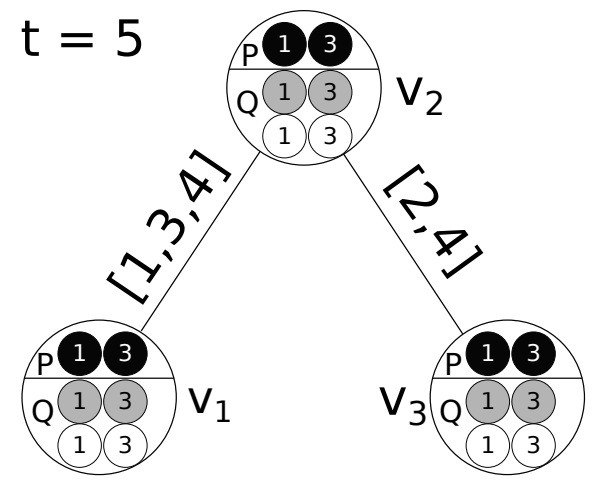

(f)

Figura 4.2: Simulação do algoritmo de Ricart e Agrawala com três nós. 
$1 \leq i<k$. Analogamente, se não existe $J_{v, u}$, o pedido de $u$ pode até chegar a $v$, mas sua resposta nunca chegará a $u$. Logo, $u$ nunca conseguirá utilizar o recurso, ou seja, não existe um instante de tempo $j>i$ tal que $\lambda_{j}(u)=(U, P, Q)$. Portanto, $C_{3}$ é uma condição necessária para o algoritmo.

\section{Condição Suficiente}

Hipótese forte da progressão: Neste algoritmo, devemos assumir que, em cada instante, toda componente conexa formada pela rede primeiramente sincroniza as listas de pedidos e respostas de todos os nós através da regra de comunicação. Em seguida, os nós realizam todas as regras monádicas possíveis e, depois, a componente é sincronizada novamente. Desta forma garantimos que todas as conexões são consideradas pelo algoritmo.

Proposição 4. A condição $C_{4}=$ para todo par de nós u e $v$ em $V(\mathcal{G})$, u e v estão conectados a termo, acrescida da hipótese forte da progressão, é uma condição suficiente para o algoritmo dado.

Prova: 1) Segurança é garantida: Vamos provar que em cada instante de tempo, pode haver no máximo um vértice utilizando o recurso. Suponha que, em um dado momento, existem dois nós $u$ e $v$ em $V(\mathcal{G})$ executando a seção crítica (ou seja, no estado $(U, P, Q)$ ). Isso significa que ambos os nós receberam pelo menos $N-1$ respostas, que os permitiu executar a segunda regra do protocolo de entrada. Considere os pedidos enviados por estes dois nós para obter o recurso. Devido a ordem total imposta pelas marcas de tempo dos pedidos e pelos identificadores dos nós, um dos pedidos tem precedência sobre o outro. Suponha que $u$ fez o pedido de menor prioridade. Como $u$ está no estado $(U, P, Q)$, isso quer dizer que este nó recebeu $N-1$ respostas, incluindo uma de $v$. Entretanto, o pedido de $v$ tem precedência sobre o de $u$, ou seja, $v$ não pode ter enviado uma resposta para $u$, uma vez que um nó só envia uma resposta se está ocioso (primeira regra de atualização de conjunto) ou se o pedido recebido tem maior prioridade (segunda regra de atualização de conjunto). Portanto, chegamos a uma contradição. Logo, não pode haver mais de um nó no estado $(U, P, Q)$ em um dado instante, então, a segurança é garantida.

2) Vivacidade é garantida: Vamos provar que, se a condição $C_{4}$ vale na rede $\mathcal{G}$, então todo nó que realiza o protocolo de entrada, em algum momento consegue acesso ao recurso. Suponha que, num dado instante, existe um conjunto $S_{R} \in V(\mathcal{G})$ de nós requisitando o recurso (no estado $\left.\left(R, n, t_{l}, A, P, Q\right)\right)$. Devido à condição $C_{4}$, existe uma jornada futura de cada nó de $S_{R}$ para todo outro nó em $V(\mathcal{G})$. Sabemos também que os pedidos enviados pelos nós em $S_{R}$ são totalmente ordenados. Considere o pedido de maior prioridade segundo esta ordem total. Devido à condição $C_{4}$ e à hipótese forte da progressão, o pedido enviado por este nó alcançará todos os outros nós da rede. Como este pedido tem a maior prioridade entre os nós em $S_{R}$, todo nó que o recebe envia sua resposta imediatamente, executando a segunda regra de atualização de conjunto se estiver em $S_{R}$ ou a primeira, se não estiver. Novamente, devido à condição $C_{4}$ e à hipótese forte da progressão, as respostas enviadas alcançarão o nó que enviou o pedido de maior prioridade, que, para cada resposta, executa a terceira regra de atualização de conjunto. Portanto, este nó receberá $N-1$ respostas, então, será capaz de executar a segunda regra do protocolo de entrada e acessar o recurso. Consequentemente, se, um dado instante, existe um conjunto de nós requisitando o recurso, aquele que tiver a maior prioridade conseguirá, em algum momento, acessá-lo. Além disso, como existe uma ordem total nos pedidos e, após liberar o recurso, o pedido satisfeito deixa de ser o de maior prioridade, os pedidos de cada nó de $S_{R}$ irão, em algum momento, passar a ser o pedido de 
maior prioridade. Portanto, como cada processo que envia um pedido, em algum momento obtém o recurso, a propriedade da vivacidade é garantida.

\subsubsection{Requisitos Computacionais}

A formalização proposta para o algoritmo de Ricart e Agrawala, facilita a verificação de condições sobre a topologia da rede. Ao mesmo tempo, vale ressaltar que esta formalização não torna sua implementação computacionalmente inviável. Entretanto, algumas observações sobre o tamanho do rótulo de cada nó e sobre o número de regras que devem ser executadas a cada instante devem ser feitas.

Um rótulo é composto de um caractere $(R, U$, ou $O)$, dois inteiros que representam o instante de emissão do pedido e o número de respostas recebidas, a lista de permissões recebidas $(A)$, a lista de pedidos $(P)$ e a lista de respostas $(Q)$. A lista $A$ pode ser implementada com um vetor de tamanho $N$ indexado pelo identificador único de cada nó da rede, no qual uma posição contém valor 1 se aquele nó está na lista e 0 caso contrário. A lista $P$ de pedidos também pode ser implementada como um vetor indexado por identificador de processos no qual o valor de uma posição é -1 se não há nenhum pedido daquele nó ou $t$ se existe um pedido emitido no instante $t$. Se um processo conseguir o recurso e emitir um novo pedido, o antigo pode ser descartado (uma vez que um novo pedido só pode ser enviado se o primeiro obteve sucesso), portanto, basta sobrescrever a posição correspondente do vetor. A lista $Q$ de respostas pode ser implementada como uma matriz indexada pelo identificador dos processos, onde cada posição $(i, j)$ guarda o instante do pedido feito pelo processo $j$ e respondido pelo processo $i$. Assim como na lista de pedidos, as respostas mais recentes (isto é, respostas cujos tempos de emissão do pedido são maiores) podem sobrescrever as mais antigas. Assim, o rótulo é composto por $N^{2}+2 N+3$ inteiros, onde $N$ é o número de processos na rede.

A cada instante, para garantir o funcionamento correto do algoritmo, é necessário primeiramente sincronizar as listas de pedidos e respostas de todos os vértices de cada componente conexa do grafo que representa o estado da rede naquele instante. Em seguida, cada nó deve realizar todas as regras monádicas que forem possíveis e, então, a componente deve ser sincronizada novamente. Para sincronizar uma componente de tamanho $K$, o número de mensagens enviadas é variável. Se cada nó enviar uma mensagem para cada um dos outros, por exemplo, $K(K-1)$ mensagens serão enviadas. Por outro lado, o número de regras monádicas executadas é variável pois depende do conteúdo de cada lista. No pior caso, um nó pode ter que reagir a uma resposta ou a um pedido (mas não aos dois) de cada um dos nós da rede e mudar seu estado para $U$. Então, no máximo $N$ regras serão executadas por nó a cada instante de tempo.

\subsection{Algoritmo de Helary et al.}

Nesta seção, apresentaremos um estudo do algoritmo de Helary et al. com base no arcabouço de Casteigts et al.

Assim como no algoritmo anterior, todos os nós iniciam no estado ocioso e um deles detém o token inicialmente. O protocolo de entrada consiste na disseminação de um pedido por todos os nós da rede, assim como no algoritmo de Ricart e Agrawala. Os pedidos também são marcados com o tempo do relógio lógico de forma a criar a mesma relação de ordem total. Em seguida, o nó que fez 
o pedido espera uma mensagem com o token para entrar na seção crítica.

Os nós que não detém o token apenas retransmitem os pedidos e respostas que chegam a eles. O nó que está com o token, se não estiver na seção crítica, verifica se há algum pedido pendente, escolhe o de maior prioridade e envia uma resposta com o token para o nó que emitiu este pedido. A resposta também é marcada com o tempo lógico de envio para que os nós saibam qual resposta é mais recente. No protocolo de saída, o nó que estava utilizando o recurso volta a ficar ocioso e marca o tempo lógico do seu último pedido atendido.

\subsubsection{Formalização}

Assim como no algoritmo anterior, todos os nós devem guardar uma lista de pedidos. A lista de respostas não é necessária, dado que no máximo uma resposta estará ativa na rede em qualquer momento. Além disso, é preciso guardar os instantes de tempo lógico do último pedido atendido de cada nó, para que se possa determinar quais pedidos ainda não foram atendidos. Logo, o rótulo de cada nó incluirá as seguintes estruturas, que serão disseminadas pela rede por meio da regra de comunicação da mesma forma que no algoritmo anterior:

- $P$ conjunto de requisições recebidas cujos elementos tem a estrutura: (processo que requisitou, marca de tempo da requisição);

- $Q$ mensagem de token com a estrutura: (nó destino, marca de tempo da requisição, marca de tempo do envio da mensagem);

- $S$ vetor indexado pelo identificador dos processos, guardando, para cada nó, o instante de tempo lógico em que seu último pedido foi atendido ou -1 se isso ainda não ocorreu.

- Alfabeto: O estado do nó pode ser $(U, T, P, Q, S)$ (usando e com o token), $(R, T \mid N, t, P, Q, S$ ) (requisitando, pode estar com $(T)$ ou sem $(-)$ o token e com o pedido enviado no tempo lógico $t),(I, T \mid-, P, Q, S)$ (ocioso, pode estar com $(T)$ ou sem $(-)$ o token). A notação $t_{l}$ sempre irá se referir ao tempo lógico do processo no instante em que ele executa a regra em questão. Cada nó guarda os conjuntos $P, Q$ e $S$, como definido anteriormente.

- Definições

1. Seja $u$ o nó que detém o token no instante $i$. Definimos $X_{i}=\left\{(\right.$ orig, $t) \in P_{u}$ tal que $S_{u}[$ orig $]<$ $t\}$ o conjunto de pedidos na rede no instante $i$ que ainda não foram satisfeitos. Note que somente os pedidos que chegaram em $u$ estarão em $P_{u}$ e $S_{u}$ contém a informação atualizada de quais pedidos já foram atendidos, já que $u$ detém o token. Deste modo, só faz sentido computar o conjunto $X_{i}$ para o nó que detém o token no instante $i$.

2. Definimos como maxPri $\left(X_{i}\right)$ o pedido de maior prioridade que está em $X_{i}$, ou seja, o pedido não atendido que possui menor tempo lógico, desempatando, se necessário, pelo menor identificador de nó.

3. Definimos maxTmsg $\left(Q_{1}, Q_{2}\right)$ a mensagem de token, dentre $Q_{1}$ e $Q_{2}$ cujo tempo lógico da resposta é maior.

4. A união entre dois arrays $S_{u}$ e $S_{v} S_{u} \cup S_{v}$ é definida como o array $S_{m}$, em que $S_{m}[i]:=$ $\max \left(S_{u}[i], S_{v}[i]\right)$, para toda posição $i$. 
- Estado inicial: Todos os nós iniciam no estado $(I,-, \emptyset, \emptyset, S[1 \ldots N]=-1)$, exceto o nó (que pode ser qualquer um da rede) que possui o token e, portanto, começa no estado $(I, T, \emptyset, \emptyset, S[1 \ldots N]=-1)$.

- Objetivo: A meta do algoritmo é garantir as propriedades de segurança e vivacidade. Os objetivos sobre o grafo evolutivo rotulado $(\mathcal{G}, \lambda)$ são:

1. A cada instante de tempo $i$, não existem dois nós $u$ e $v$ em $V(\mathcal{G})$ tal que $\lambda_{i}(u)=\lambda_{i}(v)=$ $(U, T, P, Q, S)$ (Segurança).

2. A cada instante de tempo $i$ e para todo nó $u$ em $V(\mathcal{G})$, se $\lambda_{i}(u)=(R, *, t, P, Q, S)$, então existe um instante de tempo $j>i$ tal que $\lambda_{j}(u)=(U, T, P, Q, S)$ (Vivacidade).

- Protocolo de entrada:

1. pré-condição: $\lambda_{i}(v)=(I, *, P, Q, S)$

ação: $\lambda_{i}(v):=\left(R, *, t_{l}, P \cup\left\{v, t_{l}\right\}, Q, S\right)$

(O nó muda seu estado para $R$ e emite um pedido)

2. Pré-condições: $\lambda_{i}(v)=\left(R, *, t_{p}, P, Q=\left(v, t_{p}, t_{r}\right), S\right)$

Ações: $\lambda_{i}(v):=(U, T, P, Q, S)$

(O nó recebe o token e entra na seção crítica)

- Protocolo de saída: pré-condição: $\lambda_{i}(v)=\left(U, T, P, Q=\left(v, t_{p}, t_{r}\right), S\right)$

ação: $\lambda_{i}(v):=\left(I, T, P, Q, S[v]:=t_{p}\right)$

(O nó sai da seção crítica, volta ao estado $I$ e marca o tempo do seu último pedido em $S$ )

- Regra de comunicação:

1. Requisitos topológicos: Uma componente conexa $W$ no instante $i$ tal que $\lambda_{i}(u)=\left(*, *, P_{u}, Q_{u}, S_{u}\right)$ para todo $u \in W$

Ações: Para cada $u \in W, \lambda_{i}(u)=\left(*, *, \bigcup_{v \in W} P_{v}, \operatorname{maxTmsg}\left(Q_{u}, Q_{v}\right), \bigcup_{v \in W} S_{v}\right)$

(Todo nó de toda componente conexa no instante $i$ sincroniza suas listas de pedidos e respostas e seus vetores $S$, não importando em que estado estão).

- Regras Monádicas:

1. Pré-condições: $\lambda_{i}(v)=(I \mid R, T, P, Q, S) \wedge X_{i} \neq \emptyset \wedge(j, t)=\max \operatorname{Pri}\left(X_{i}\right)$ Ações: $\lambda_{i}(v):=\left(I \mid R,-, P, Q:=\left(j, t, t_{l}\right), S\right)$

(O nó que tem o token determina qual o pedido de maior prioridade na rede calculando o conjunto $X$ e envia o token para o nó que emitiu este pedido)

A Figura 4.3 mostra uma simulação do algoritmo de Helary et al. na mesma situação da simulação anterior.

- Inicialmente, em 4.3(a), os nós $v_{1}$ e $v_{3}$ pedem o recurso e $v_{2}$ detém o token no instante 0.

- Em 4.3(b), $v_{1}$ e $v_{2}$ se comunicam e $v_{1}$ recebe uma resposta com o token e entra na seção crítica. 


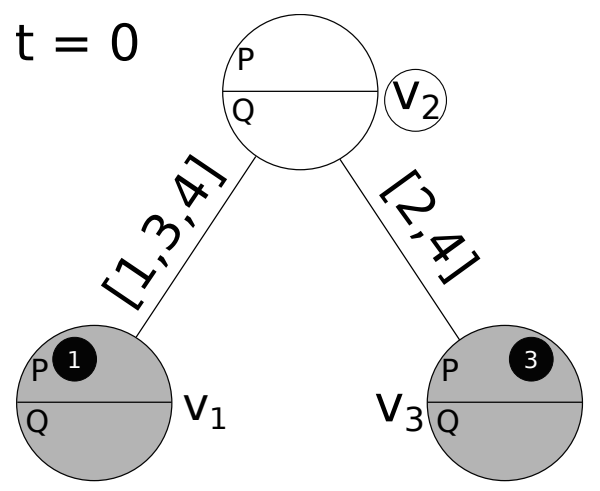

(a)

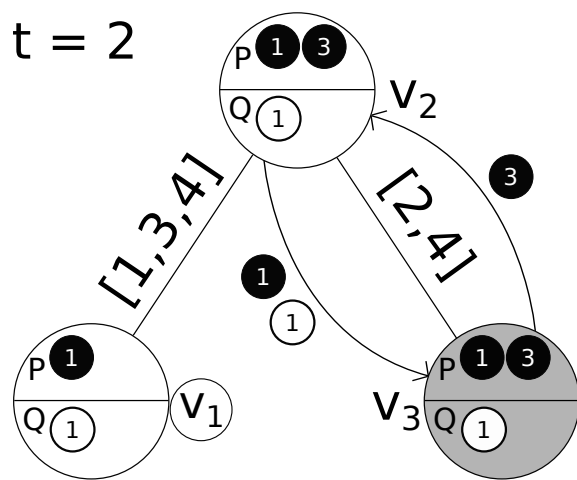

(c)

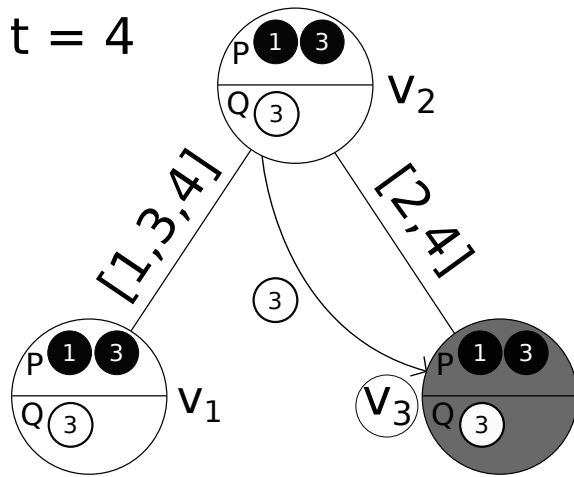

(e)

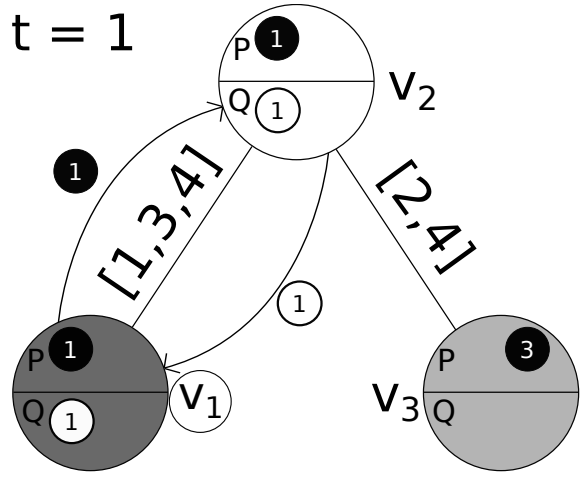

(b)

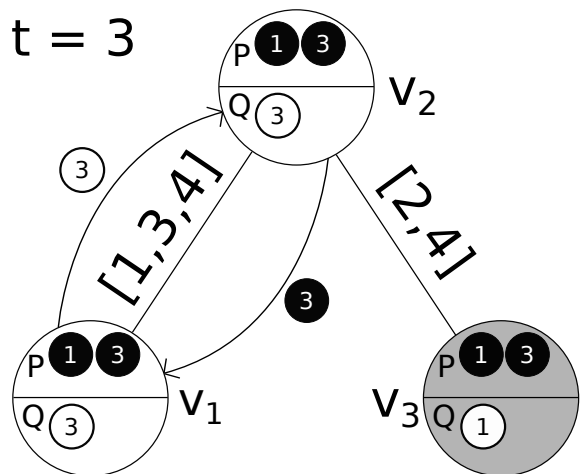

(d)
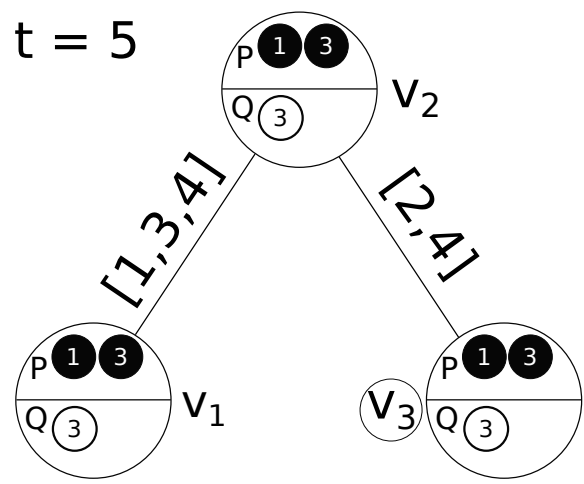

(f)

Figura 4.3: Simulação do algoritmo de Helary et al. com três nós. 
- Em 4.3(c), $v_{1}$ termina de utilizar o recurso e $v_{2}$ recebe o pedido de $v_{3}$ e envia o pedido e resposta de $v_{1}$.

- Em $4.3(\mathrm{~d}), v_{1}$ recebe o pedido de $v_{3}$ e envia uma resposta com o token.

- Em 4.3(e), $v_{3}$ recebe a resposta e entra na seção crítica.

- Finalmente, em 4.3(f), $v_{3}$ sai sa seção crítica e os três nós estão ociosos novamente.

\section{Condição Necessária}

Não é possível descrever uma condição necessária para este algoritmo. Uma condição necessária é uma condição tal que, se ela não valer em uma determinada rede, nenhuma execução do algoritmo será possível. Mas, para qualquer condição que fixarmos, existe uma execução que funcionará, qualquer que seja a rede, que é o caso em que apenas o nó que detém o token inicialmente faz pedidos para entrar na seção crítica. Por este motivo, vamos adicionar a suposição de que pelo menos dois nós diferentes realizam o protocolo de entrada.

Proposição 5. Seja $\mathcal{R}(\mathcal{G})=\left\{u \in V(\mathcal{G}) \mid \exists i \lambda_{i}(u)=(R, *, t, P, Q, S)\right\}$ o conjunto de todos os nós que requisitam o recurso em algum momento mais o nó que detém o token inicialmente. Considere a condição $C_{5}(\mathcal{G})=$ Para cada par de nós u e $v$ em $\mathcal{R}(\mathcal{G})$, existe pelo menos uma jornada de u para $v$ ou uma de $v$ para $u$.

Primeiramente, uma consideração sobre esta condição. Se existir $J_{u, v}$ apenas, existem casos de execução em que o algoritmo funciona. Considere que $\mathcal{R}(\mathcal{G})=\{u, v, w\}$ e que o token começa com o nó $u$. Este requisita o recurso e o utiliza. O pedido de $w$ chega em $u$ e o token é transmitido para $w$. Não existe mais jornada entre $u$ e $w$. Em seguida, o pedido de $v$ chega em $w$ e existe uma jornada entre $w$ e $v$, logo, $v$ também consegue o token, mesmo sem existir $J_{v, u}$. As propriedades de segurança e vivacidade foram preservadas.

Prova: Vamos provar que para todo grafo evolutivo $\mathcal{G}$, se $C_{7}$ não vale em $\mathcal{G}$, então existe um instante de tempo $i$ e um vértice $u$ em $V(\mathcal{G})$ tal que $\lambda_{i}(u)=(R, N, t, P, Q, S)$ e, para todo instante de tempo $j>i, \lambda_{j}(u) \neq(U, T, P, Q, S)$. Ou seja, provaremos que se existe algum par de nós em $\mathcal{R}(\mathcal{G})$ que não se conecta por ao menos uma jornada, a propriedade da vivacidade é violada.

Sejam $u$ e $v$ dois nós em $\mathcal{R}(\mathcal{G})$ tal que não existe $J_{u, v}$ nem $J_{v, u}$. Como tanto $u$ quanto $v$ estão em $\mathcal{R}(\mathcal{G})$, ambos requisitam o recurso em algum momento ao longo da execução da rede. Se nenhum dos nós receber o token em nenhum momento, então eles não conseguirão entrar na seção crítica e logo, a vivacidade é violada. Considere então, sem perda de generalidade, que o nó $u$ recebe o token em algum momento. Se $v$ receber o token em algum momento após $u$ ter recebido, isso quer dizer que existe uma jornada de $u$ para $v$, o que é uma contradição. Portanto, se $u$ entrar na seção crítica, então $v$ nunca entrará. Logo, a vivacidade é violada e, portanto, $C_{5}$ é uma condição necessária para o algoritmo.

\section{Condição Suficiente}

Proposição 6. Considere a condição $C_{6}(\mathcal{G})=$ Todo par de nós u e v em $\mathcal{R}(\mathcal{G})$ está conectado a termo. $C_{6}$, acrescida da hipótese forte da progressão, é uma condição suficiente para o algoritmo dado. 
Prova: 1) Segurança é garantida: Vamos provar que, a todo momento, ou existe um único nó com o token $(T)$ ou existe uma resposta circulando pela rede que ainda não foi recebida por seu destino final.

Inicialmente, um nó está no estado $I$ e com o token $(T)$, então a condição vale no início. Ao enviar o token em uma mensagem, este nó executa a regra monádica e fica sem o token $(N)$. Esta mensagem só pode ser recebida por um único nó e apenas uma vez, pois a regra monádica restringe o nó que recebe a mensagem e o tempo lógico do pedido que será atendido. Ou seja, se um nó voltar a requisitar o recurso, seu tempo lógico será maior e, logo, a mesma mensagem de token não fará com que este nó entre na seção crítica. Ao receber uma mensagem de token, o nó passa ao estado $U$ e, por fim, I novamente, portanto, a propriedade vale em todo este ciclo. Como uma nova resposta só será emitida quando a anterior tiver sido satisfeita, apenas uma resposta ativa pode circular pela rede. Logo, a propriedade vale em todo instante. Então, como existe no máximo um nó no estado $U$, a segurança é preservada.

2) Vivacidade é garantida: Vamos provar que, se a condição $C_{6}$ vale em $\mathcal{G}$, então todo nó que realiza a primeira regra do protocolo de entrada em algum momento, executará a segunda regra do protocolo de entrada.

Como a condição $C_{6}$ e a hipótese forte da progressão valem na rede $\mathcal{G}$, então, todo nó que faz um pedido está no conjunto $\mathcal{R}(\mathcal{G})$ e, portanto, seus pedidos em algum momento chegam em um nó que detém o token. Analogamente, toda mensagem enviada com o token também sempre chega a seu destino.

Vale notar que, uma vez que um pedido chega ao nó que tem o token, este não sairá do conjunto $X$ até que seja atendido, pois quando a mensagem de token é enviada para outro nó, os pedidos também são, bem como o vetor $S$. Logo, o conjunto $X$ e o vetor $S$ sempre estão atualizados no nó que está com o token e, portanto, a regra monádica determina corretamente o conjunto de pedidos não atendidos dentre aqueles conhecidos pelo nó que detém o token para calcular o de maior prioridade (a regra considera todos os pedidos em $P$ cujo nó correspondente possui valor de $S$ menor do que o tempo lógico do pedido). Deste modo, basta mostrar que todo pedido que está no conjunto $X$ será atendido.

Considere que o nó $u$ está com o token no instante $i$. Se $u$ desejar entrar na seção crítica, deve emitir um pedido, que entrará no conjunto $X_{i}$. Se existe algum pedido neste conjunto, o nó deverá enviar uma mensagem de token para aquele de maior prioridade. Os pedidos em $X_{i}$ são totalmente ordenados, então, $u$, enviará esta mensagem para o primeiro pedido nesta ordenação utilizando a regra monádica. Ao receber a resposta, o nó entra na seção crítica e, ao realizar o protocolo de saída, marca o tempo lógico do seu pedido realizado no vetor $S$, o que faz com que seu pedido saia do conjunto $X$ e deixe de ser o de maior prioridade. Se este nó emitir outro pedido, a prioridade dele será menor, já que seu relógio lógico é incrementado a cada mensagem. Portanto, como os pedidos estão totalmente ordenados, o pedido de maior prioridade sempre é atendido e todo pedido atendido deixa de ser o de maior prioridade, todos os pedidos no conjunto $X$ de um nó que detém o token serão atendidos em algum momento. E, como todo pedido em algum momento chega ao nó com o token, todo pedido feito é atendido. Portanto, a vivacidade é preservada.

Podemos notar que a condição $C_{6}$ leva em conta conhecimento sobre quais nós da rede vão fazer pedidos. Se este conhecimento estiver disponível, então, o algoritmo de Helary et. al requer uma condição de conectividade mais fraca do que o de Ricart e Agrawala. Do contrário, a condição $C_{6}$ 
considerará que o conjunto $\mathcal{R}(\mathcal{G})$ de nós que fazem pedidos é igual ao conjunto de nós $V(\mathcal{G})$ da rede e, portanto, obtemos a condição $C_{4}$, a mesma do algoritmo de Ricart e Agrawala.

\section{Requisitos Computacionais}

Assim como o algoritmo de Ricart e Agrawala, esta formalização também não é excessivamente custosa para a implementação do algoritmo de Helary et al. Cada rótulo guarda dois caracteres $(I|R| U$ e $T \mid-)$, um tempo lógico $(t)$, uma lista de pedidos $(P)$, uma resposta $(Q)$ e um vetor $(S)$. A lista $P$ de pedidos pode ser implementada como um vetor de tamanho $N$ ( $N$ é o número de nós na rede) indexado por identificador de processos no qual o valor de uma posição é -1 se não há nenhum pedido daquele nó ou $t$ se existe um pedido emitido no instante $t$. O vetor $S$ tem tamanho $N$ e guarda apenas inteiros. Todos os outros campos tem tamanho constante. Assim, o rótulo é composto por $2 N+5$ inteiros, um tamanho consideravelmente menor do que no algoritmo de Ricart e Agrawala.

A cada instante, toda componente conexa deve sincronizar as listas de pedidos, as respostas e o vetor $S$. Como visto anteriormente, uma componente de tamanho $K$ troca no máximo $K(K-1)$ mensagens para sincronizar. A diferença neste algoritmo é que temos que sincronizar dados de tamanho $O(N)$ ao invés de $O\left(N^{2}\right)$ como era no algoritmo anterior, portanto, a sincronização será mais rápida. O número de regras monádicas executadas é proporcional ao número de nós que executam o protocolo de entrada, pois, para cada uma destas execuções, rodam duas regras para o protocolo de entrada, uma para o de saída e uma regra para criar a resposta para este nó.

Por esta análise, podemos perceber que o algoritmo de Helary et al. é mais eficiente em termos de espaço utilizado em cada nó e número de mensagens circulando pela rede, o que é especialmente importante no caso de uma rede dinâmica.

\subsection{Estendendo o Problema: K-Exclusão Mútua}

Uma possível extensão do problema da exclusão mútua distribuída é considerar que não existe apenas um recurso, mas $K$ deles, compartilhados pelos nós do sistema. De forma similar ao problema da exclusão mútua com apenas um recurso, as propriedades de segurança e vivacidade devem ser garantidas, exceto que a segurança é redefinida da seguinte forma: a cada instante de tempo, no máximo $K$ nós estão na seção crítica (isto é, utilizando uma das $K$ unidades do recurso).

Para este problema, estudaremos o algoritmo proposto por Raymond [Ray89a], que é uma simples extensão do algoritmo de exclusão mútua de Ricart e Agrawala. Cada nó que deseja utilizar o recurso deve assegurar que existe pelo menos uma das $K$ unidades disponível. Então, ele envia pedidos a todos os outros $N-1$ nós e espera por $N-K$ respostas, que são suficientes para determinar que nem todas as $K$ unidades estão em uso.

Quando um processo recebe um pedido, ele responde se está no estado ocioso ou se a requisição tem precedência sobre a sua pŕopria. A prioridade dos pedidos é definida da mesma forma que no algoritmo de Ricart e Agrawala. Quando um nó termina de usar uma unidade do recurso, ele manda respostas a todos os nós cujos pedidos ele adiou a resposta. Pode haver mais de um pedido enviado pelo mesmo nó, mas, só é necessário enviar resposta ao mais recente, visto que qualquer outro que exista já terá sido satisfeito. Todas as respostas recebidas além das $N-K$ são ignoradas. 


\subsubsection{Formalização}

As únicas diferenças entre a formalização do algoritmo de Ricart e Agrawala e o de Raymond são o objetivo que representa a segurança, que passa a expressar que no máximo $K$ nós podem usar o recurso simultaneamente e a segunda regra do protocolo de entrada, que é executada quando o nó recebe $N-K$ mensagens, ao invés de $N-1$.

- Alfabeto: $(I, P, Q)$ (ocioso), $(U, P, Q)$ (utilizando), $\left(R, n, t_{l}, A, P, Q\right)$ (requisitando, o pedido foi enviado com tempo lógico $t_{l}, n$ respostas foram obtidas e todos os nós no conjunto $A$ responderam ao pedido). $P$ e $Q$ são, respectivamente, a lista de pedidos e respostas recebidas, como definido anteriormente.

- Estado inicial: Todo nó começa no estado $(I, \emptyset, \emptyset)$.

- Objetivo: A meta do algoritmo é garantir as propriedades de segurança e vivacidade. Os objetivos sobre o grafo evolutivo rotulado $(\mathcal{G}, \lambda)$ são:

1. A cada instante de tempo $i$, não existem $K+1$ nós $v_{1}, v_{2}, \ldots, v_{K+1}$ em $V(\mathcal{G})$ tal que $\lambda_{i}\left(v_{k}\right)=(U, P, Q)$ para $k$ entre 1 e $K+1$ (Segurança).

2. A cada instante de tempo $i$ e para todo nó $u$ em $V(\mathcal{G})$, se $\lambda_{i}(u)=\left(R, n, t_{l}, A, P, Q\right)$, então existe um instante de tempo $j>i$ tal que $\lambda_{j}(u)=U$ (Vivacidade).

- Protocolo de entrada: (regras monádicas)

1. Pré-condições: $\lambda_{i}(v)=(I, P, Q)$

Ações: $\lambda_{i}(v)=\left(R, 0, t_{l}, \emptyset, P \cup\left\{\left(v, t_{l}\right)\right\}, Q\right)$

( $O$ nó $v$ muda seu estado para $R$ e adiciona seu próprio pedido a $P$ ).

2. Pré-condições: $\lambda_{i}(v)=\left(R, N-K, t_{l}, A, P, Q\right)$

Ações: $\lambda_{i}(v):=(U, P, Q)$

( $O$ nó $v$, que está requisitando, obtém $N-K$ respostas e pode usar o recurso).

- Protocolo de saída: (regra monádica)

Pré-condições: $\lambda_{i}(v)=(U, P, Q)$

Ações: $\lambda_{i}(v)=\left(I, P, Q \cup\left\{\left(p, v, t_{l}\right) \mid\left(p, t_{l}\right) \in P\right\}\right)$

( $O$ nó $v$ muda seu estado para $I$ e registra em $Q$ que enviou respostas para todos os pedidos pendentes).

- Regra de comunicação:

Requisitos topológicos: Uma componente conexa $C \subseteq V\left(G_{i}\right)$ tal que $\lambda_{i}(u)=\left(*, P_{u}, Q_{u}\right)$ para todo $u \in C$

Ações: Para cada $u \in C, \lambda_{i}(u)=\left(*, \bigcup_{v \in C} P_{v}, \bigcup_{v \in C} Q_{v}\right)$

(Todo nó de toda componente conexa no instante $i$ sincroniza suas listas de pedidos e respostas, não importando em que estado estão).

- Regras monádicas de atualização de conjuntos:

1. Pré-condições: $\lambda_{i}(v)=(I, P, Q) \wedge \exists(p, t) \in P,\left(p, v, t_{l}\right) \notin Q$

Ações: $\lambda_{i}(v):=\left(I, P, Q \cup\left(p, v, t_{l}\right)\right)$

( $O$ nó $v$ está ocioso e tem uma requisição pendente para a qual ainda não enviou resposta). 
2. Pré-condições: $\lambda_{i}(v)=\left(R, n, t_{l_{1}}, A, P, Q\right) \wedge \exists\left(p, t_{l_{2}}\right) \in P,\left(p, v, t_{l_{2}}\right) \notin Q \wedge\left(t_{l_{1}}>t_{l_{2}} \vee\left(t_{l_{1}}=\right.\right.$ $\left.\left.t_{l_{2}} \wedge i d(p)<i d(v)\right)\right)$

Ações: $\lambda_{i}(v):=\left(R, n, t_{l_{1}}, A, P, Q \cup\left(p, v, t_{l_{2}}\right)\right)$

(O pedido de $p$ tem precedência sobre o de $v$ e $v$ ainda não enviou resposta para $p$ ).

3. Pré-condições: $\lambda_{i}(v)=\left(R, n, t_{l}, A, P, Q\right) \wedge \exists p,\left(v, p, t_{l}\right) \in Q \wedge p \notin A$.

Ações: $\lambda_{i}(v):=\left(\left(R, n+1, t_{l}, A \cup\{p\}\right), P, Q\right)$

( $O$ nó $v$ recebeu uma resposta de $p$ para seu pedido; $v$ deve registrar que a resposta de $p$ apenas se esta resposta ainda não foi registrada).

\subsubsection{Condição Necessária}

Novamente, faz-se necessária a suposição de que ao menos um nó execute o protocolo de entrada para que a condição seja realmente necessária.

Proposição 7. Seja u um nó em $V(\mathcal{G})$, definimos $N(u)=\left\{v \in V(\mathcal{G}) \mid \exists J_{u, v}\right.$ e $\left.J_{v, u}\right\}$ o conjunto de todos os nós da rede para os quais existem jornadas de ida e volta de $u$. A condição $C_{7}(\mathcal{G})=$ para todo vértice u em $V(\mathcal{G})$, a cardinalidade de $N(u)$ é pelo menos $N-K$ é uma condição necessária para o algoritmo dado.

Prova: Vamos provar que para todo grafo evolutivo $\mathcal{G}$, se $C_{7}$ não vale em $\mathcal{G}$ então existe um instante de tempo $i$ e um vértice $u$ em $V(\mathcal{G})$ tal que $\lambda_{i}(u)=\left(R, n, t_{l}, A, P, Q\right)$ e, para todo instante de tempo $j>i, \lambda_{j}(u) \neq U$.

Suponha que existe um nó $u$ em $V(\mathcal{G})$ e um instante de tempo $i$ tal que $\lambda_{t}(u)=\left(R, 0, t_{l}, \emptyset, P, R\right)$ e que $|N(u)|<N-K$. Os vértices em $N(u)$ são os únicos capazes de receber o pedido de $u$ e de enviar uma resposta que alcance $u$ em algum momento. Mas, como $|N(u)|<N-K, u$ receberá no máximo $N-K-1$ respostas e, logo, nunca atingirá o estado $(R, N-K, t, A, P, Q)$, e, consequentemente, nunca será capaz de executar a segunda regra do protocolo de entrada. Portanto, $u$ nunca conseguirá usar uma das unidades do recurso, isto é, não existe um instante de tempo $j>i$ tal que $\lambda_{j}(u)=(U, P, Q)$. Logo, $C_{7}$ é uma condição necessária para o algoritmo.

\subsubsection{Condição Suficiente}

Proposição 8. Seja u um nó em $V(\mathcal{G})$, definimos $N^{\prime}(u)=\{v \in V(\mathcal{G}) \mid$ u esta conectado a termo a $v\}$ o conjunto de todos os nós da rede conectados a termo a u. A condição $C_{8}(\mathcal{G})=$ para todo nó u em $V(\mathcal{G})$, a cardinalidade de $N^{\prime}(u)$ é pelo menos $N-K$, acrescida da hipótese forte da progressão, é uma condição suficiente para o algoritmo dado.

Prova: 1) Segurança é garantida: Vamos provar que em cada instante de tempo, pode haver no máximo $K$ vértices utilizando o recurso. Suponha que, em um dado momento, existe um conjunto $S_{U} \subseteq V(\mathcal{G})$ de nós utilizando unidades do recurso (estado $(U, P, Q)$ ) e que $\left|S_{U}\right|>K$. Isso significa que cada nó em $S_{U}$ recebeu pelo menos $N-K$ respostas, que os possibilita executar a segunda regra do protocolo de entrada. Considere os pedidos enviados por estes nós para conseguir uma unidade do recurso. Os pedidos são totalmente ordenados, conforme consideramos as marcas de tempo e os identificadores dos nós associados aos pedidos. Seja $u$ o nó em $S_{U}$ cujo pedido é o $K+1$-ésimo maior na ordem total mencionada. Como $u$ teve que receber $N-K$ respostas para atingir o estado $U$ e 
existem $K$ nós cujo pedido tem precedência sobre o de $u$, isso quer dizer que $u$ obteve resposta de pelo menos um destes $K$ nós, o que é uma contradição, visto que um nó só responde a um pedido se estiver ocioso (primeira regra de atualização de conjunto), ou se o pedido recebido tem precedência sobre o seu (segunda regra de atualização de conjunto). Portanto, não podem existir mais do que $K$ nós no estado $(U, P, Q)$ em um dado momento, logo, a segurança é preservada.

2) Vivacidade é preservada: Vamos provar que, se a condição $C_{8}$ vale na rede $\mathcal{G}$, então todo nó que realiza o protocolo de entrada, em algum momento consegue acesso ao recurso. Suponha que, num dado instante, existe um conjunto $S_{R} \subseteq V(\mathcal{G})$ ) de nós requisitando o recurso na rede. Devido à condição $C_{8}$, existe uma jornada futura iniciando em cada nó em $S_{R}$ e terminando em pelo menos $N-K$ outros nós. Sabemos também que os pedidos enviados pelos nós em $S_{R}$ são totalmente ordenados. Considere o pedido de maior prioridade segundo esta ordem total. Devido à condição $C_{8}$ e à hipótese forte da progressão, o pedido enviado por este nó alcançará pelo menos $N-K$ nós. Como este é o pedido de maior prioridade na rede, todo nó que o receber responderá imediatamente, executando a segunda regra de atualização de conjunto se estiver em $S_{R}$ e a primeira caso contrário. Novamente devido à condição $C_{8}$ e à hipótese forte da progressão, as respostas enviadas chegarão ao nó que enviou o pedido de maior prioridade. Para cada resposta recebida, este nó executa a terceira regra de atualização de conjunto. Portanto, este nó receberá pelo menos $N-K$ respostas, e será capaz de executar a segunda regra do protocolo de entrada e acessar uma unidade do recurso. Consequentemente, se, em um dado instante de tempo, existe um conjunto de nós requisitando uma unidade do recurso, aquele que tiver o pedido de maior prioridade conseguirá utiliza-lo em algum momento. Além disso, como os pedidos seguem uma ordem total e, após liberar uma unidade do recurso, o pedido é satisfeito e deixa de ter a maior prioridade, todo nó em $S_{R}$ irá, em algum momento, ter o pedido de maior prioridade. Portanto, como cada nó que requisita uma unidade do recurso consegue obtê-la em algum momento a propriedade da vivacidade é garantida.

Uma observação interessante é que a condição $C_{8}$ pode implicar em uma condição mais forte. Como cada nó da rede deve estar conectado a termo a pelo menos outros $N-K$, o tamanho mínimo de uma componente (neste caso, denotamos por componente um conjunto maximal de nós que são dois a dois conectados a termo) é $N-K+1$. Portanto, se $N-K+1>N / 2$, isso significa que a menor componente no grafo deve conter mais da metade de todos os nós do grafo, o que implica que o grafo tem uma única componente e que todo nó está conectado a termo com todos os outros. Ou seja, nestas condições, $C_{4}$ vale nesta rede.

\subsubsection{Requisitos Computacionais}

Os requisitos computacionais para o algoritmo de Raymond são exatamente os mesmos que os discutidos para o algoritmo de Ricart e Agrawala. Como as estruturas e regras usadas pelos algoritmos são as mesmas, o espaço utilizado e o número de mensagens trocadas é o mesmo. 


\section{Capítulo 5}

\section{Ferramenta para Análise de Rastros}

\subsection{Motivação}

A maioria dos trabalhos que envolvem redes dinâmicas têm pelo menos uma parte de caráter puramente experimental, em que os autores visam validar suas teorias ou algoritmos utilizando algum tipo de simulação. Para isso, muitos trabalhos utilizam dados de redes dinâmicas reais [uma, cra] em suas simulações, pois estes geram resultados mais próximos da realidade do que simulações com padrões sintéticos de movimentação. Estes dados obtidos de sistemas reais são chamados de rastros (traces) e são muito utilizados na literatura [BLV08, BGJL06].

Apesar do grande número de trabalhos desenvolvidos sobre rastros de redes dinâmicas, existe muito pouca informação sobre os rastros em si. Não é possível saber, por exemplo, se um rastro tem conectividade alta ou baixa, se existem certos períodos em que há mais conexões ativas, se todos os nós são alcançáveis, quanto as jornadas entre nós demoram, entre outras informações que podem afetar drasticamente os algoritmos que executam nesta rede. Por estes motivos, atualmente é uma tarefa difícil escolher um rastro apropriado para avaliar ou validar um protocolo de roteamento ou outro algoritmo distribuído.

Devido a esta dificuldade, os pesquisadores que utilizam rastros devem desenvolver seus próprios programas para verificar se o rastro satisfaz as suposições necessárias para seu estudo. Dentre as suposições comuns, estão a de periodicidade, ou seja, que as conexões se repetem em intervalos de tempo do mesmo tamanho; as de conectividade, que variam desde componentes conexas até a densidade do grafo; e até sobre a duração das conexões, pois se forem muito curtas, podem não ser aproveitadas.

Outra situação bastante comum na literatura são os trabalhos que propõem novos algoritmos de roteamento para DTNs ou MANETs. Para validar seus algoritmos, os autores costumam fazer comparações com outros algoritmos de roteamento. Apesar destas comparações serem úteis para determinar a melhor abordagem para determinadas situações, sem o desenvolvimento de uma ferramenta própria para verificação daquela rede, não é possível saber quanto os resultados ficam próximos dos valores ótimos na rede para entrega de mensagens, latência média, e outras métricas.

Por estes motivos, desenvolvemos sistema para análise de rastros de redes dinâmicas capaz de extrair as informações mencionadas por meio da construção de um grafo evolutivo e da execução de determinados algoritmos sobre esta estrutura. Com o sistema DTNTES (Delay Tolerant Network Trace Evaluator System), é possível obter métricas úteis sobre a rede, dados de conectividade, informações sobre as jornadas ótimas, e outras em formato visual ou em formato texto. 
Com esta ferramenta, um pesquisador terá meios de avaliar os rastros disponíveis antes de escolher qual utilizar para seus testes. As opções visuais de conectividade fornecem dados que permitem verificar se um rastro é esparso ou denso, o alcance dos nós, o número de conexões ativas ao longo do tempo e a estabilidade dos nós. Como o desempenho de certos algoritmos depende fortemente da topologia da rede, estes dados podem ajudar a determinar este comportamento e a justificar ganhos e perdas no desempenho. No caso de pesquisadores que criam algoritmos de roteamento e os testam nos rastros, a opção de jornadas permite verificar os caminhos ótimos para entrega de mensagens de forma a comparar os resultados do novo protocolo com os melhores resultados possíveis naquele rastro.

Nas próximas seções, detalharemos o funcionamento da ferramenta DTNTES e mostraremos um estudo de caso com o rastro da rede DieselNet e como a ferramenta afetaria alguns trabalhos que utilizam esta rede em seus resultados.

\subsection{Implementação da Ferramenta DTNTES}

Para prover dados sobre um rastro de rede dinâmica, utilizamos a modelagem de grafos evolutivos. Ao representar a rede neste formato, ganhamos toda a base combinatória proveniente desta estrutura e todos os algoritmos já existentes sobre ela. Desta forma, podemos utilizar as propriedades combinatórias para extrair informações sobre a rede para que sejam utilizadas em simulações.

Para implementar estas ferramentas de análise, utilizamos a mesma estrutura de grafos evolutivos já utilizada em trabalhos anteriores [GFM10, GFMF10]. Este programa implementa os grafos como listas de adjacências em que cada aresta é uma lista de intervalos no qual ela está ativa e pode ser percorrida. Utilizando este formato, é possível trabalhar com tamanhos arbitrários de intervalos (não necessariamente inteiros). Além disso, o sistema implementa os algoritmos para jornadas ótimas e facilita a implementação das outras funcionalidades mencionadas.

Para disponibilizar estas funcionalidades publicamente, foi implementado um sistema web, pois desta forma, ele é facilmente acessível a toda a comunidade científica que trabalha com redes dinâmicas, não necessita de instalação e facilita o compartilhamento de dados. Apesar disso, o código fonte do sistema estará disponível se algum pesquisador quiser instalá-lo em um servidor local.

A ferramenta DTNTES foi desenvolvida em linguagem Java, pois a estrutura de grafos evolutivos citada está implementada nesta linguagem. O framework web utilizado foi o Google Web Toolkit (GWT), que permite a criação de aplicativos portáveis e eficientes e permite que o programador preocupe-se mais com as funcionalidades do que com a adaptabilidade a diferentes navegadores. Além disso, este framework disponibiliza o Google Chart Tools, uma API que cria e mostra gráficos interativos de vários tipos de maneira fácil e direta. A Figura 5.1 mostra a página inicial do sistema.

Primeiramente, o usuário deve fazer upload do seu rastro em um dos formatos suportados pelo programa (detalhados a seguir). O sistema interpreta este rastro e constrói o grafo evolutivo correspondente, e o guarda para usos posteriores. O grafo é guardado no sistema em um formato próprio, desenvolvido para facilitar a leitura e interpretação. O arquivo informa o número de nós e o número de arestas. Para cada aresta, existe uma linha no arquivo com as pontas inicial e final, o tempo que esta aresta leva para ser percorrida e a lista de intervalos de tempo na qual a aresta está ativa. Com este formato, a construção do grafo é feita aresta a aresta, não havendo necessidade de guardar 


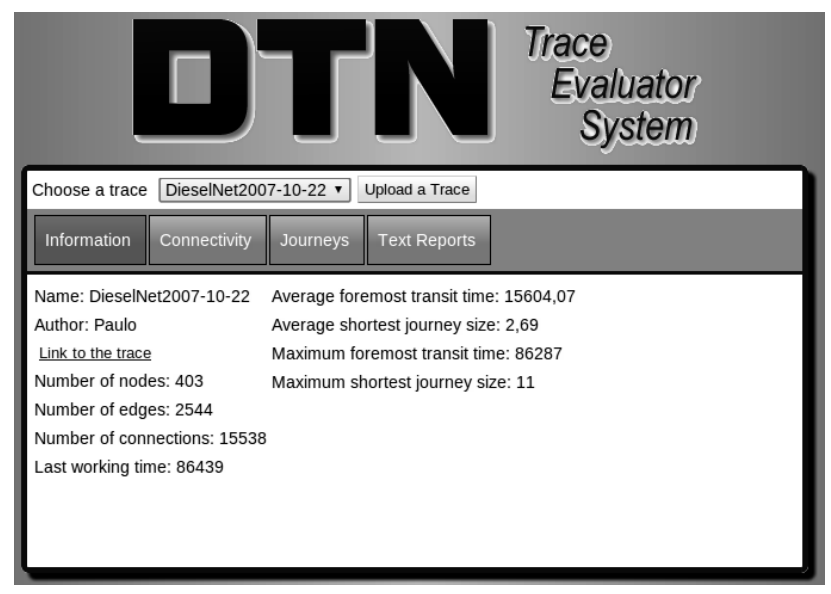

Figura 5.1: Tela inicial do sistema DTNTES.

nenhum dado extra.

A entrada de dados do programa atualmente aceita apenas três tipos de formatos: o formato descrito anteriormente, o formato aceito pelo simulador ONE [KOK09] e o formato utilizado nos arquivos do rastro DieselNet. A adição de novos formatos é bastante simples e consiste apenas na criação de uma nova classe leitora e adição na interface visual. Apesar da leitura ser feita de diferentes maneiras, os rastros sempre são guardados no formato padrão, pois este é mais adaptado para a recuperação dos dados. A persistência é feita com arquivos simples, mas pode ser facilmente extendida para um banco de dados.

A funcionalidade do sistema consiste em uma série de serviços que podem ser executados sobre os rastros. Estes serviços são divididos em dados relacionados à conectividade e à jornadas. Nas seções seguintes, detalharemos a utilidade e a implementação de cada serviço da ferramenta DTNTES.

\subsubsection{Serviços de Conectividade}

A conectividade da rede é um dos aspectos mais importantes que um pesquisador deve considerar na hora de escolher um rastro para seu trabalho. As informações sobre a conectividade podem alterar radicalmente a interpretação dos resultados de um estudo feito sobre o rastro, pois algoritmos podem ter comportamentos diferentes dependendo da frequência dos encontros entre os nós. Por este motivo, a maior ênfase da ferramenta é prover informações que permitam caracterizar a densidade das conexões de um rastro.

Com este objetivo, o sistema fornece cinco gráficos agregando as informações sobre a conectividade: porcentagem de conexões diretas, porcentagem de conexões por jornadas, número de conexões ativas por instante de tempo, porcentagem de pares conectados por jornadas em cada instante de tempo e índice de estabilidade dos nós. Além disso, o sistema apresenta quatro métricas para estimar o grau de separação dos nós tanto no espaço quanto no tempo. As medidas relativas ao comprimento das jornadas são muito comuns no estudo de redes complexas [LFM+10]. As medidas relativas ao tempo de chegada são equivalentes às de espaço, mas adaptadas ao contexto de jornadas. São estas o tempo médio e o tempo máximo de trânsito das jornadas foremost e o comprimento médio e máximo das jornadas shortest (também chamado diâmetro do grafo).

O gráfico de porcentagem de conexões diretas por nó mostra, para cada nó $u$ do grafo, o tamanho do conjunto de nós $S$ tal que existe uma aresta $u v$ para todo $v$ em $S$ dividida pelo número total 
de nós. Para calcular este conjunto basta percorrer, para cada nó, a lista de adjacências e contar o número de arestas na lista. Se, com estes dados, fizessemos uma curva, os dados não ficariam claros o suficiente, pois o identificador dos nós não possui uma ordenação que ajude na visualização. Portanto, os nós foram agrupados pelo intervalo de porcentagem e, com isso, um gráfico de barras mostra a informação mais claramente.

Com este gráfico, é possível verificar o grau dos nós, se existem nós hubs (que possuem muitas conexões e, portanto, são importantes para a conectividade geral da rede) e é possível ter uma ideia da densidade do grafo, pois se existem muitos nós com baixos percentuais de conectividade direta, então o grafo é esparso. Um exemplo deste gráfico pode ser visto na Figura 5.2.

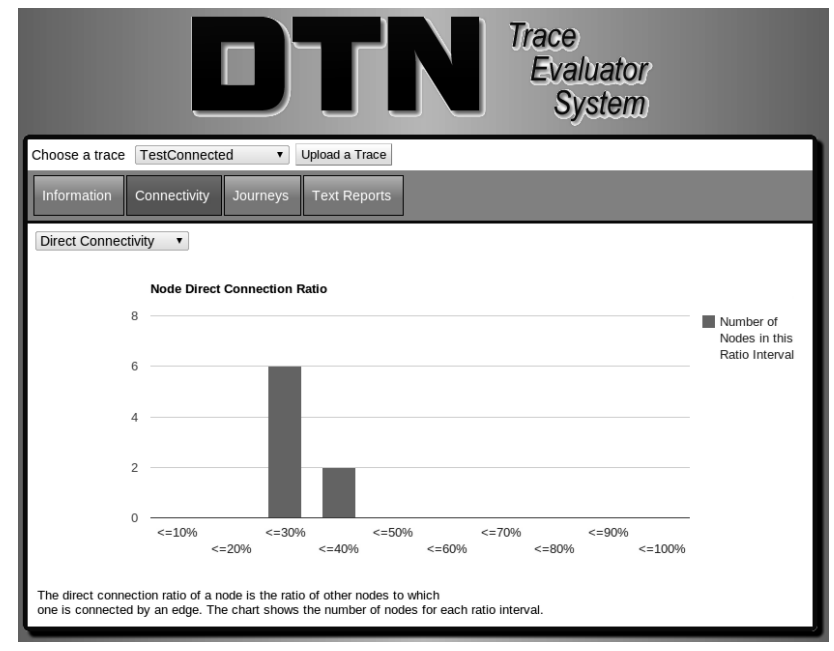

Figura 5.2: Exemplo de gráfico de conectividade direta na ferramenta DTNTES.

Para determinar a conectividade do grafo ao longo do tempo, o sistema fornece o gráfico de porcentagem de conexões por jornadas por nó. Para cada nó $u$, é mostrada a porcentagem de nós $v$ do grafo para os quais existe pelo menos uma jornada entre $u$ e $v$. Da mesma forma que o gráfico anterior, estas informações são agrupadas pelo intervalo de porcentagem em um gráfico de barras. Para calcular este número, foi utilizado o algoritmo que calcula, para um nó, todas as jornadas foremost deste nó para outro no grafo. Executando este algoritmo para todos os nós, basta contar quantas jornadas o algoritmo devolve para cada nó. Ao invés da jornada foremost, outro algoritmo poderia ter sido utilizado, mas os mesmos resultados seriam obtidos, porém, o algoritmo escolhido é o mais rápido dentre os cálculos de jornadas.

Com este gráfico é possível verificar o alcance dos nós ao longo do tempo. Nós que alcançam poucos outros conseguem entregar menos mensagens do que nós conseguem se comunicar com muitos outros por jornadas. Se a maioria dos nós tem alcance baixo, isso quer dizer que o grafo está fragmentado em componentes são pequenas. Em caso contrário, se muitos nós possuem conectividade ao longo do tempo alta, então o grafo possui uma componente que contém a maioria dos nós. Um exemplo deste gráfico pode ser visto na Figura 5.3.

Os dois gráficos anteriores mostram a conexão entre os nós como algo estático, que existe durante todo o tempo na rede, mas isto não é verdade. As conexões, tanto diretas como por jornadas, podem cair logo no início do tempo e os números do gráfico podem ser enganosos. Por este motivo, os gráficos a seguir são muito importantes, pois eles mostram os mesmos dados, número de conexões diretas e número de conexões por jornadas, ao longo do tempo. 


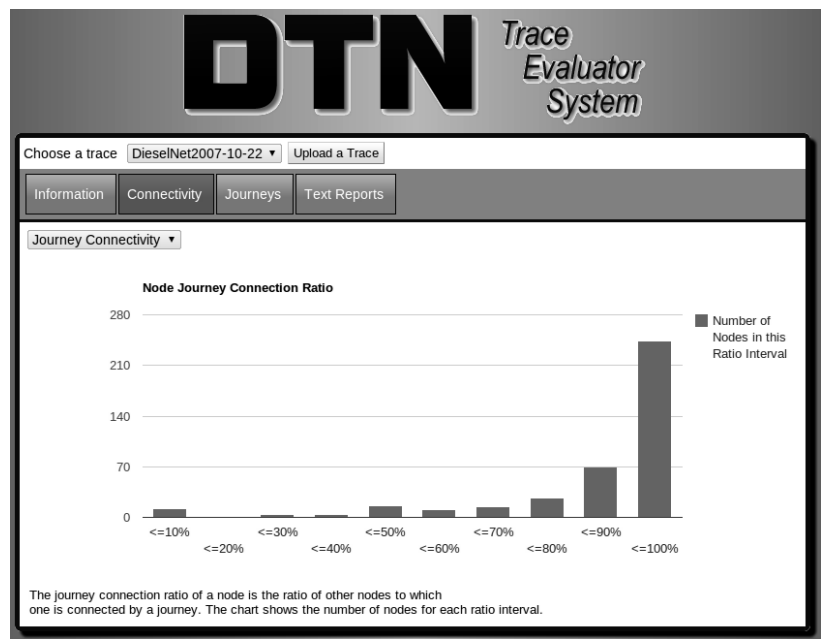

Figura 5.3: Exemplo de gráfico de conectividade por jornadas na ferramenta DTNTES.

O gráfico de número de conexões ativas por instante de tempo foi calculado iterando sobre todas as conexões diretas na rede e incrementando o contador de conexões dos instantes de tempo em seu intervalo. Este gráfico mostra os períodos em que a conectividade da rede cresce ou diminui. Períodos de conectividade alta são mais propícios para entrega de mensagens ou execução de outros algoritmos distribuídos e conhecer períodos de baixa conectividade pode ajudar a economizar energia dos nós, em caso de redes móveis. Um exemplo deste gráfico pode ser visto na Figura 5.4.

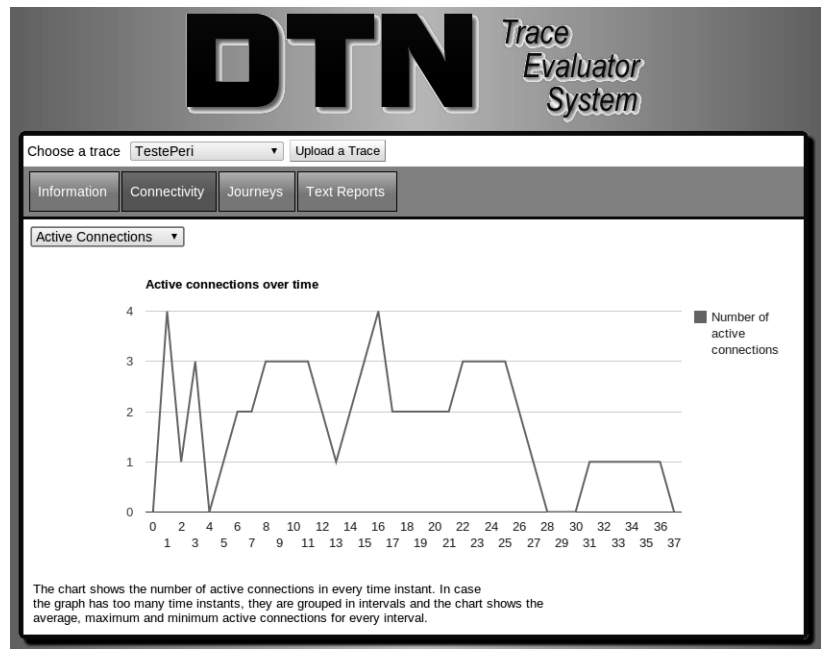

Figura 5.4: Exemplo de gráfico de conexões ativas ao longo do tempo na ferramenta DTNTES.

O gráfico de número de conexões por jornadas em cada instante de tempo foi implementado utilizando um algoritmo derivado da jornada foremost que calcula a jornada que sai do nó de origem no instante mais tarde possível. Este algoritmo é chamado Latest Journey. Calculamos a jornada latest para todos os nós da rede e colocamos o tempo de saída de cada uma delas em uma lista. Ordenando-se esta lista em ordem decrescente, o primeiro tempo é o momento em que a última conexão termina e assim por diante, portanto, basta contar as conexões em cada intervalo de tempo.

Neste gráfico, é possível ver o decaimento da conectividade da rede com o tempo. A curva nunca cresce, pois se existe uma jornada no futuro, isso quer dizer que qualquer mensagem gerada antes 
do instante de saída desta jornada poderá ser entregue. Logo, nesta curva, é possível identificar os momentos em que a conectividade da rede cai permanentemente, bem como a conectividade geral da rede, que é o valor observado logo no início. Esta informação é muito útil para determinar até qual instante vale a pena depender de comunicação entre os nós. Um exemplo deste gráfico pode ser visto na Figura 5.5.

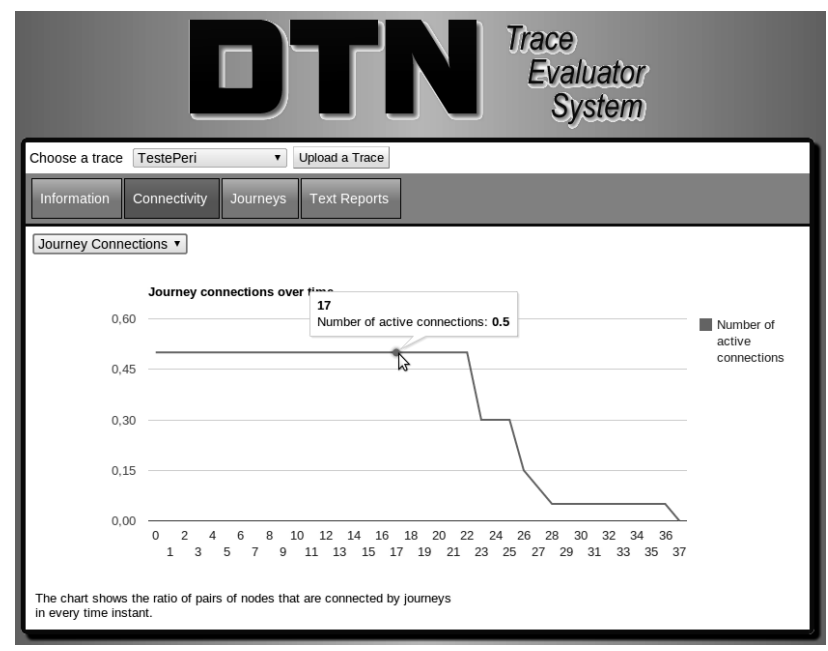

Figura 5.5: Exemplo de gráfico de conexões por jornadas ao longo do tempo na ferramenta DTNTES.

Para determinar a importancia de um único nó para a conectividade geral da rede, o gráfico de estabilidade pode ser utilizado. O índice de estabilidade de um nó é definido como a diferença entre o número de pares conectados por jornadas na rede quando este nó e removido e o mesmo valor para a rede original. Este valor aponta a queda que ocorre na conectividade da rede se este nó falhar. Esta métrica é muito útil para determinar se existem nós hub na rede e sua proporção. Um exemplo deste gráfico pode ser visto na Figura 5.6.

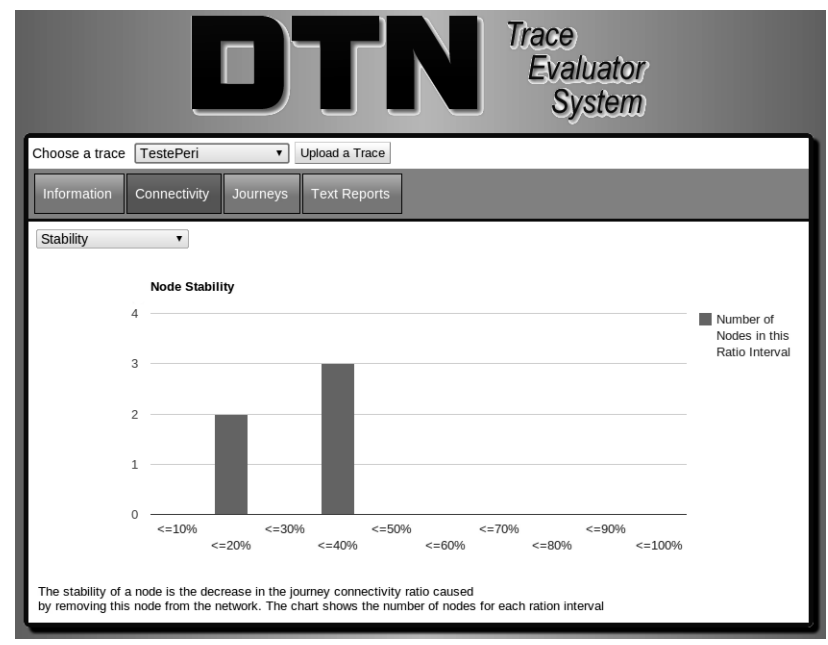

Figura 5.6: Exemplo de gráfico de estabilidade na ferramenta DTNTES.

Além dos gráficos, as informações sobre conectividade de cada nó em particular pode ser obtida em um relatório de texto, para processamento por um computador ou uma agregação diferente destas informações. O relatório mostra, para cada nó, todos os outros nós com os quais este se conecta, o maior instante de conexão total e o último instante de conexão. 


\subsubsection{Serviços de Jornadas}

A segunda classe de serviços fornecida pelo sistema DTNTES é o de determinar as jornadas ótimas entre os pares de nós em cada instante de tempo. Estas informações são úteis no desenvolvimento de protocolos de roteamento, pois o algoritmo gera uma rota entre os nós que dificilmente será ótima e a existência de um limite inferior para comparações é extremamente importante. Na maioria dos estudos sobre este assunto atualmente, a validação de um protocolo é feita apenas através de comparações com outros protocolos já existentes. O problema desta abordagem é que todos os protocolos possuem casos ruins, em que os resultados obtidos não são bons. As jornadas ótimas sempre fornecem o melhor resultado possível, independente do caso, sendo, então, uma base mais confiável para este tipo de estudo.

O sistema permite que o usuário escolha o nó de origem, o nó destino e o instante de tempo de início e, com estas informações, mostra a jornada foremost, seu instante de chegada, a jornada shortest e seu comprimento. O formato de exibição das jornadas mostra a sequência de nós, com os respectivos instantes de conexão entre cada par de nós. Em caso de a jornada ser vazia (quando o nó origem e o destino são iguais) ou quando não existe jornada, uma mensagem apropriada é mostrada. A tela de jornadas pode ser vista na Figura 5.7.

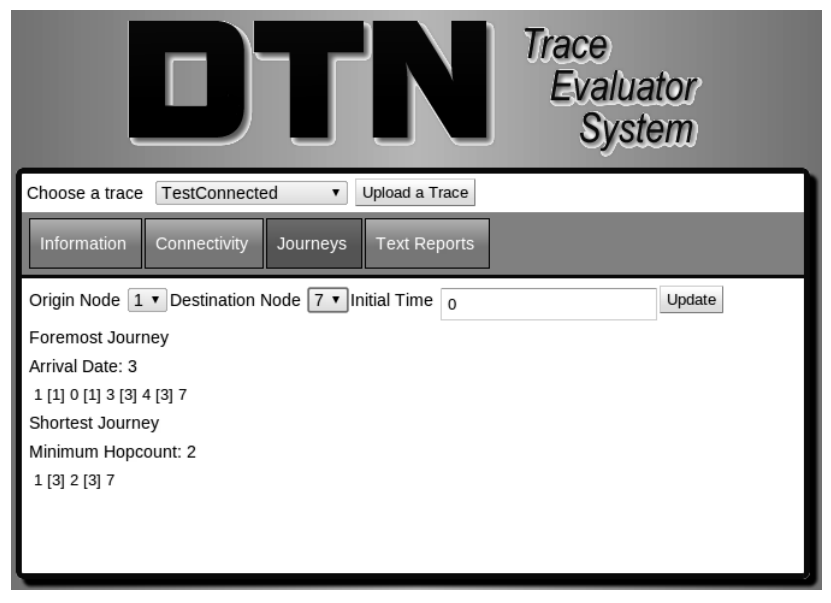

Figura 5.7: Exemplo da tela de visualização de jornadas na ferramenta DTNTES.

Além desta interface amigável, relatórios em texto com as jornadas completas e os dados de instante de chegada e comprimento ótimos são fornecidos. As informações destes relatórios são as mesmas obtidas através da interface visual, mas agrupadas em formato texto para facilitar o processamento automático.

As informações individuais sobre as jornadas ótimas na rede são úteis quando o usuário deseja visualizar um número pequeno de jornadas rapidamente e em detalhes, mas no caso de muitas jornadas serem necessárias, o método perde sua eficiência. Por este motivo, a ferramenta fornece também o serviço de processamento de um log de mensagens. Basta que o usuário faça o upload de um arquivo contendo, em cada linha, o nó de origem, o nó de destino e o instante de criação de uma mensagem para que o sistema devolva um relatório com o tempo mínimo de chegada e o menor número de saltos possível para aquela jornada naquela rede. Este serviço facilita a comparação entre os resultados de um protocolo de roteamento e os resultados ótimos para uma rede e é especialmente importante para pesquisadores que utilizam rastros no estudo de protocolos de roteamento. 


\subsubsection{Periodicidade}

Outro aspecto de redes dinâmicas abordado na ferramenta DTNTES é a periodicidade das conexões. Dizemos que uma aresta é periódica, se existe um padrão nas conexões e desconexões que se repete várias vezes ao longo do tempo. Se todas as arestas de uma rede forem periódicas, a rede é periódica também. Esta característica é importante para diversos algoritmos, já que ela implica que toda conexão sempre se repetirá no futuro, portanto, a conectividade da rede nunca se altera.

O problema de detectar um padrão nas conexões de uma aresta é similar ao de busca de padrões em textos. Porém, como o padrão buscado não é conhecido, é preciso testa-los todos, o que gasta tempo quadrático no número de conexões de cada aresta e é preciso realizar o mesmo cálculo para todas as arestas da rede. O problema desta abordagem é que ela só detecta a periodicidade se o padrão for seguido rigorosamente, o que dificilmente será verdade para redes implementadas no mundo real. Deste modo, o ideal seria encontrar uma definição de periodicidade que permitisse uma certa margem de erro para que um algoritmo conseguisse resultados mais úteis sobre os dados dos rastros reais.

A ferramenta DTNTES oferece um relatório em texto sobre a periodicidade de cada aresta da rede, utilizando a abordagem rigorosa mencionada anteriormente. Uma pequena modificação permite que existe um tempo de warmup no início antes de começar a considerar a periodicidade. $\mathrm{O}$ relatório mostra, para cada aresta, o tamanho do tempo de warmup necessário e quanto tempo tem cada intervalo padrão que se repete, ou uma mensagem no caso de a aresta não ser periódica em nenhum momento. A utilidade destas informações é limitada devido aos problemas já mencionados na definição de periodicidade.

\subsection{Estudo de Caso: DieselNet}

Para demonstrar a utilidade da ferramenta desenvolvida e todas as suas funcionalidades, mostraremos, nesta seção, um exemplo de sua utilização com um rastro real da rede DieselNet [BLV08]. O objetivo deste estudo é mostrar que tipo de informações e conclusões é possível extrair de um rastro utilizando a ferramenta DTNTES e sua utilidade para os pesquisadores desta área.

A DieselNet é uma infra-estrutura de rede veicular montada no campus da Universidade de Massachusetts Amherst que cobre o campus e o município próximo. Ela é composta de 30 ônibus equipados com computadores HaCom Open Brick (CPU de $577 \mathrm{MHz}, 256 \mathrm{Mb}$ RAM) alimentados pela bateria de $24 \mathrm{~V}$. Um ponto de acesso 802.11 b está conectado ao computador e fornece acesso DHCP para os passageiros e pedestres próximos. Uma segunda interface USB 802.11b escaneia a área próxima constantemente em busca de outros ônibus e outros pontos de acesso. Cada ônibus tem também um GPS que registra sua posição e roda Linux em um HD de 40Gb.

Os rastros utilizados neste trabalho foram obtidos entre 22 de Outubro e 18 de Novembro de 2007, apenas nos dias úteis, totalizando 20 dias. Cada arquivo consiste em um dia de funcionamento da rede e mostra, para cada conexão entre dois ônibus ou entre um ônibus e um ponto de acesso externo, uma linha contendo os identificadores dos dois nós, o horário de início da conexão, a duração em segundos, a quantidade de dados transferidos e a latitude e longitude da conexão. Os arquivos de conexões entre dois ônibus e entre um ônibus e um ponto de acesso eram separados, mas foram intercalados antes de serem inseridos na ferramenta DTNTES.

Todos os arquivos do pacote de rastros de 2007 foram inseridos na ferramenta para que uma 


\begin{tabular}{|c|c|c|}
\hline Métrica & Média & Desvio Padrão \\
\hline Média dos tempos de trânsito foremost $(\mathrm{s})$ & 15909.6 & 1963.77 \\
\hline Máximo tempo de trânsito foremost $(\mathrm{s})$ & 85083.05 & 1183.35 \\
\hline Média dos comprimentos shortest (saltos) & 2.89 & 0.09 \\
\hline Máximo comprimento shortest (saltos) & 9.82 & 1.09 \\
\hline
\end{tabular}

Tabela 5.1: Médias das métricas dentre os rastros de todos os dias do DieselNet.

análise comparativa de todos os dias pudesse ser realizada. Na próxima seção, mostraremos os resultados obtidos do sistema.

Inicialmente, vamos analisar as métricas da rede fornecidas pelo sistema na página de informações. Na Tabela 5.1, os dados coletados de todos os dias do rastro foram agregados. É possível perceber que a média do tempo de trânsito (diferença entre o tempo de chegada e o tempo de partida) de uma jornada foremost entre dois nós é de quase 16000 segundos, ou seja, quase 4 horas e meia. Considerando que existem muito mais pontos de acesso na rede do que ônibus, é natural que a comunicação entre dois pontos distantes seja demorada, pois é preciso esperar que um veículo passe. O valor do tempo máximo de trânsito de uma jornada é praticamente de $24 \mathrm{~h}$, que é o tempo de funcionamento de cada arquivo.

Ao observar as métricas das jornadas shortest, é possível perceber que os nós estão, em média, a aproximadamente 3 saltos de distância um do outro. Isso implica que, em geral, uma mensagem entre dois pontos de acesso deve passar por em média dois ônibus para chegar ao seu destino. Como o tempo de chegada de uma jornada shortest é sempre maior que o da jornada foremost, podemos perceber que cada salto leva, em média mais de 1,5 hora. Conforme mostram os desvios padrões da tabela, as métricas das redes geradas pelos diferentes dias não difere muito, o que pode ser explicado pelo fato de os ônibus terem uma rota e um horário pré-fixado.

Os gráficos de conectividade direta e conectividade por jornadas mostrados nas Figuras 5.8 e 5.9 mostram que a maior parte dos nós conecta-se a menos de $10 \%$ dos outros vértices da rede diretamente, porém, percebemos, também, que a maior parte dos nós conecta-se a mais de $90 \%$ dos outros vértices por jornadas. Isso mostra que a rede tem alta conectividade por jornadas, apesar de quase todos os nós terem conectividade direta baixa. É possível inferir destes dados que existe uma componente grande no grafo, que contém quase todos os nós e podem existir componentes menores, mas estas são compostas de uma pequena fração dos nós da rede. Os gráficos de conectividade são muito similares para todos os dias do rastro, apresentando as mesmas distribuições do número de nós pelos intervalos de porcentagem.

No gráfico de conexões diretas ativas por instante de tempo, podemos perceber que existe um grande período com nenhuma conectividade, aproximadamente entre os 9000 e os 22000 segundos (aproximadamente entre as $2 \mathrm{~h} 30$ e as $6 \mathrm{~h}$ da manhã) em todos os dias do rastro. Por esta informação, podemos perceber que os ônibus têm um horário em que não circulam, logo, este tempo poderia ser ignorado por usuários do rastro, ou utilizado como período de aquecimento para os algoritmos. O número de conexões diretas ativas mantém-se praticamente constante ao longo das horas do dia, diminuindo nas horas da noite. Em alguns dias, o período sem conexões é maior, iniciando antes de 1h da manhã, o que mostra que podem haver dias em que os ônibus circulam até mais tarde. A menos desta pequena diferença, novamente, os gráficos são bastante similares ao longo dos dias. A Figura 5.10 mostra um exemplo deste gráfico. 


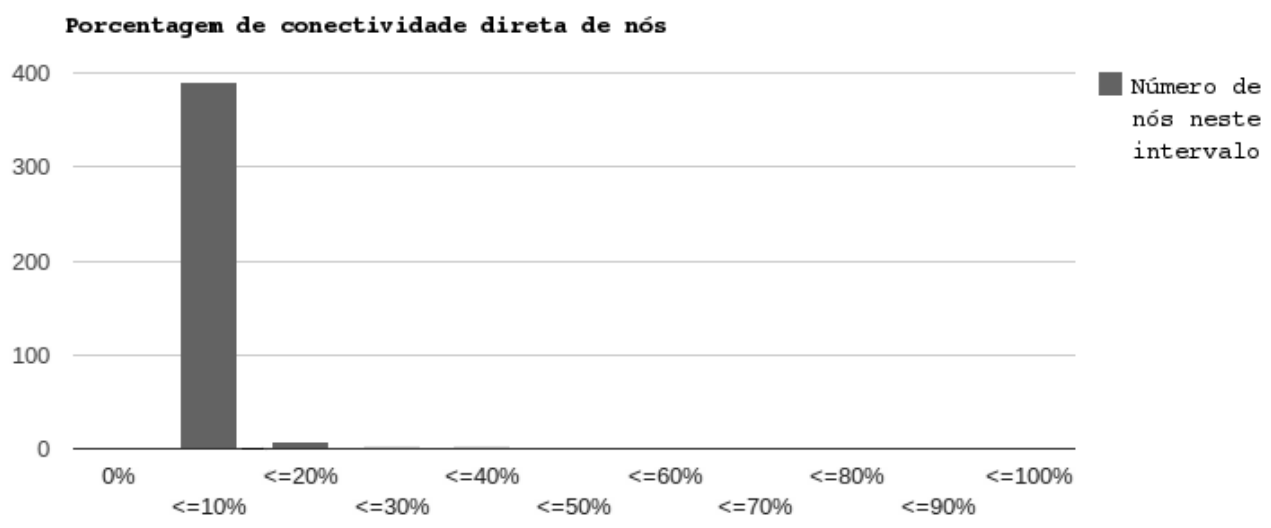

Figura 5.8: Gráfico de número de nós por intervalo de porcentagem de conectividade direta.

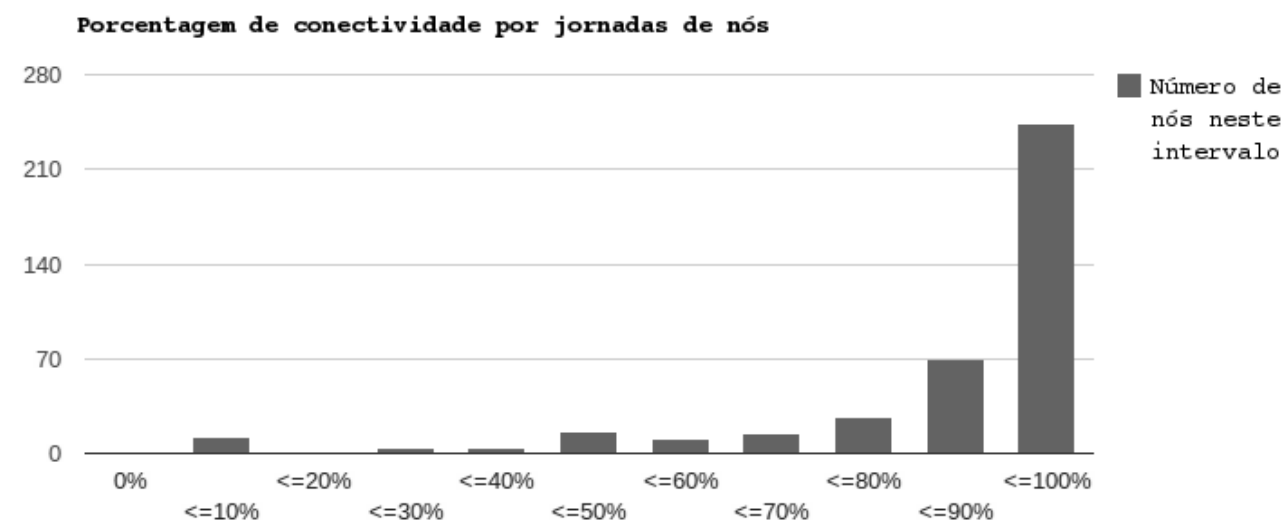

Figura 5.9: Gráfico de número de nós por intervalo de porcentagem de conectividade por jornadas.

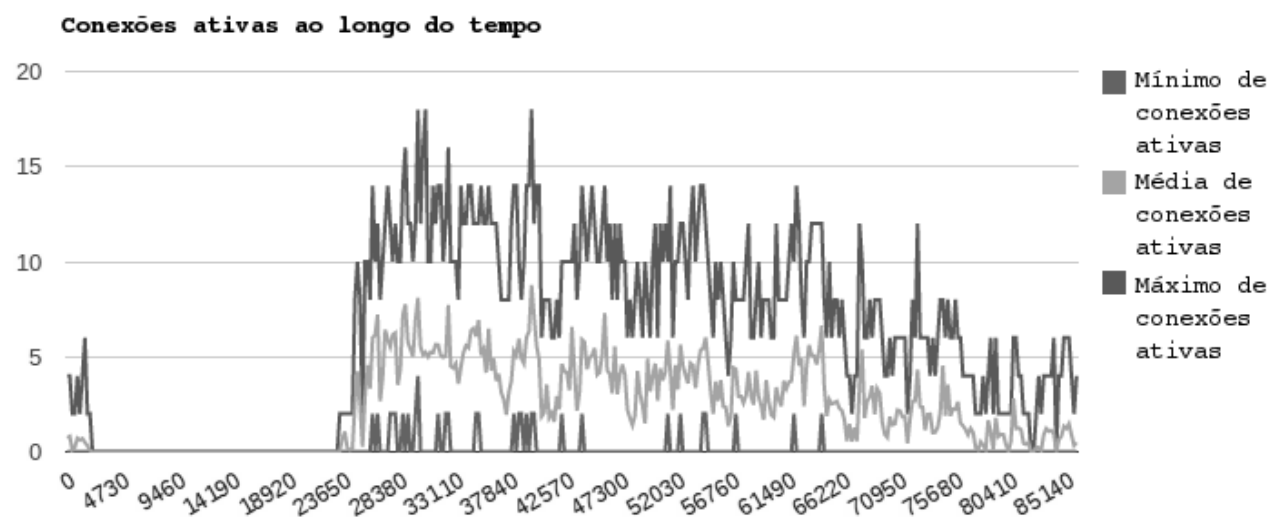

Figura 5.10: Gráfico de número de conexões diretas ativas por instante de tempo. 
No gráfico de conexões por jornadas ao longo do tempo, percebemos que a conectividade começa em aproximadamente $85 \%$ e se mantém neste nível por toda a madrugada, já que nenhuma conexão cai neste período. Ao longo do dia, a conectividade passa a cair gradativamente, o que é natural pois diversas conexões entre ônibus e ponto de acesso devem ocorrer apenas uma vez no dia. O fato de não haver quedas bruscas de conectividade indica a ausência de conexões ponte (conexões que, ao cairem, dividem o grafo em duas componentes grandes).

As curvas de conectividade são bastante parecidas em todos os dias, com todas atingindo menos de $50 \%$ de conectividade aproximadamente aos 50000 segundos $(14 \mathrm{~h})$ e menos de $25 \%$ de aproximadamente aos 65000 segundos (18h). As curvas também apresentam uma mudança na concavidade entre os $50 \%$ e $25 \%$ de conectividade, o que indica uma queda mais rápida neste ponto e mais lenta próxima ao final do rastro. A Figura 5.11 mostra um destes gráficos.

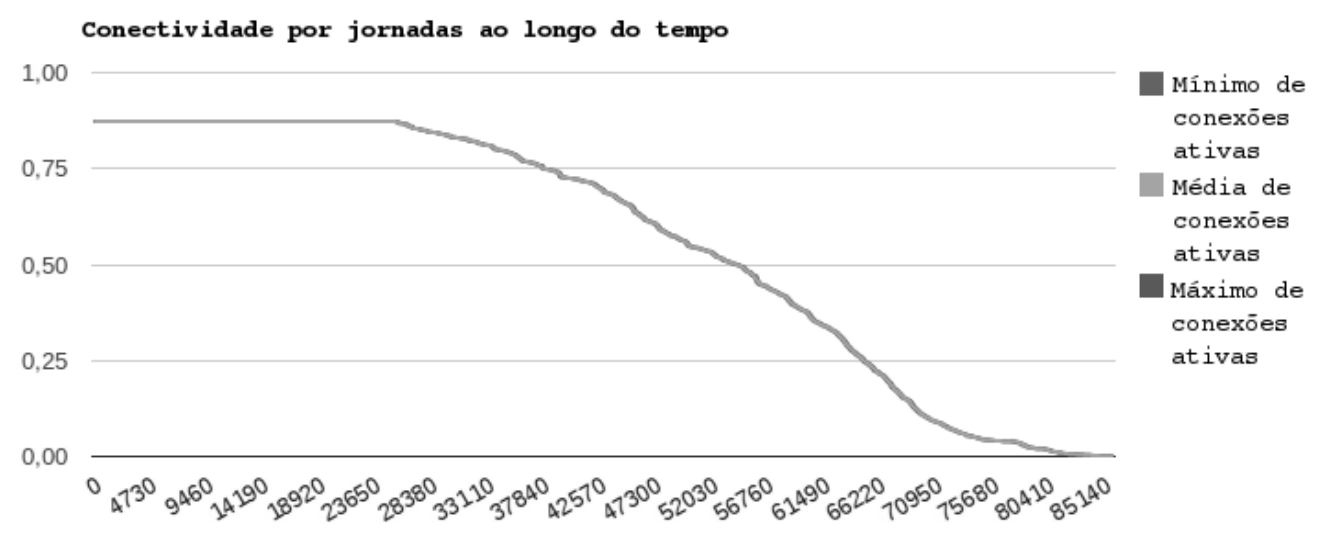

Figura 5.11: Gráfico de número de conexões diretas ativas por instante de tempo.

No gráfico de estabilidade, podemos perceber que praticamente todos os nós causam menos de $10 \%$ de desconexão na rede, se removidos. Isto vale para todos os dias do rastro, sendo que, em alguns deles, existem 1 ou 2 nós causando entre 10\% e 20\% de desconexões. Este fato mostra que os rastros da rede DieselNet são bastante estáveis e não vulneráveis a falhas isoladas. É natural que a queda de um ponto de acesso externo não deveria ter grande impacto na conectividade geral, mas era esperado que quando um ônibus parasse de funcionar, muitos pares de pontos de acesso se desconectariam. Apesar disso, como mostra o gráfico na Figura 5.6, uma única falha de ônibus não causa uma perda significativa de conectividade.

Com os dados fornecidos pela ferramenta, conseguimos extrair muitas informações sobre os rastros DieselNet que não estão disponíveis de outra forma. Descobrimos que existe um grande período em que a rede fica desligada, que a rede tem alta conectividade por jornadas, apesar de ter baixa conectividade direta. Determinamos, também, que as jornadas entre nós têm tamanho médio 3 e tempo de trânsito médio de 4 horas e meia. Foi possível concluir também que poucas falhas não provocam grande desconexão na rede, devido a sua alta estabilidade. Esta caracterização não poderia ser obtida facilmente de outra forma e tem potencial para ser muito útil para um pesquisador que deseja utilizar a rede DieselNet. 
Estabilidade dos nós

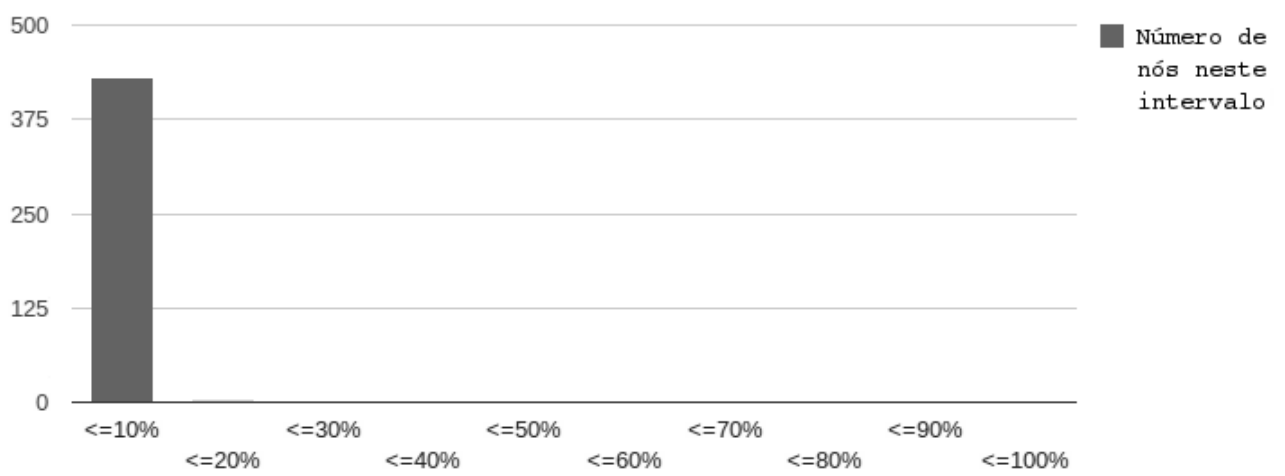

Figura 5.12: Gráfico de estabilidade. 


\section{Capítulo 6}

\section{Conclusões}

Neste trabalho, estudamos a estrutura de grafos evolutivos utilizada na modelagem de redes dinâmicas tanto no aspecto teórico quanto prático. No aspecto teórico, mostramos que a representação da topologia de redes por meio desta estrutura, se aliada a uma ferramenta teórica para definição de algoritmos pode fornecer a base necessária para a busca e formalização de condições necessárias e suficientes de topologia para o funcionamento destes algoritmos. No aspecto prático, mostramos que a construção de um grafo evolutivo a partir dos dados de conexões de uma rede dinâmica pode gerar diversas informações úteis para a caracterização desta rede.

Estudando o problema da exclusão mútua distribuída e os algoritmos de Ricart e Agrawala e Helary et al., determinamos as condições necessárias e suficientes para seu funcionamento e mostramos que a abordagem baseada em token é menos custosa do que a baseada em permissão em termos computacionais. Estudamos, também, o problema da $K$-exclusão mútua e mostramos que, ao resolver este problema com a abordagem baseada em permissão, sua complexidade fica exatamente igual à da solução para a exclusão mútua com um único recurso.

Apesar destes resultados não serem inovações no campo dos algoritmos distribuídos, acreditamos que a maior contribuição desta parte do trabalho é o amadurecimento do framework de Casteigts et al. Ao utilizá-lo para os diferentes problemas e abordagens, mostramos seu potencial na definição de algoritmos e caracterização das condições topológicas necessárias e suficientes, criando um roteiro para o estudo de um problema e seus algoritmos.

Outro resultado do trabalho desenvolvido é a estrutura utilizada para formalizar a disseminação de uma mensagem de um nó para todos os outros na rede. A ideia por trás desta estrutura é simplesmente manter em cada vértice a lista de mensagens mais recentes de cada um dos outros vértices e, a cada instante, sincronizar as listas em cada conexão. Utilizamos esta abordagem em todos os algoritmos estudados para suprir a necessidade de comunicação com um nó para o qual não se conhece um caminho e, portanto, a difusão é a única maneira de encontrá-lo. Esta estrutura pode ser utilizada em qualquer problema que apresente esta característica, sendo, assim, uma contribuição importante.

Apresentamos também, neste trabalho, a ferramenta DTNTES, incluindo detalhes de sua implementação e dos dados fornecidos referentes à conectividade das redes e às jornadas ótimas entre nós. Além disso, mostramos a utilidade desta ferramenta fazendo uma análise de um rastro real da rede DieselNet, que é utilizada em simulações por diversos trabalhos na literatura.

A ferramenta não está completa, visto que seria desejável que aceitasse mais formatos de rastros, gerasse mais informações, apresentasse formas mais amigáveis de visualização, dentre outras 
possíveis melhorias. Outro ponto em que há grande margem para evolução é na detecção de periodicidade, funcionalidade que ainda é muito limitada devido à dificuldade em se encontrar uma definição correta para o problema e, consequentemente, métodos para resolvê-lo de forma satisfatória às necessidades de um pesquisador.

Apesar de haver margem para melhorias, acreditamos que a ferramenta será útil para pesquisadores que desejam extrair informações sobre um rastro antes de utilizá-lo ou para tirar conclusões mais precisas sobre seus estudos. Da mesma forma, acreditamos também que as informações sobre jornadas entre nós e entrega de mensagens serão úteis para fornecer um limite inferior para estudos sobre protocolos de roteamento.

O trabalho de pesquisa desenvolvido sobre a modelagem de grafos evolutivos teve como frutos duas publicações em conferências internacionais. Ao obtermos os resultados iniciais sobre o problema da exclusão mútua distribuída e sobre os algoritmos de Ricart e Agrawala e Raymond, publicamos esta parte do trabalho na conferência IEEE NCA 2011 [FGA11]. Após a conclusão do estudo sobre o algoritmo de Helary et al., submetemos um novo artigo para o Simpósio Brasileiro de Redes de Computadores. Quanto ao sistema DTNTES, uma versão inicial foi apresentada como demo na conferência ExtremeCom 2011 [FG11]. Um artigo completo foi submetido recentemente para a ExtremeCom 2012.

Após trabalhar com grafos evolutivos tanto para fins teóricos quanto práticos, podemos afirmar que esta estrutura é muito poderosa e flexível e apresenta ainda muito potencial a ser explorado. Esperamos que este trabalho seja um ponto de partida para uma exploração mais profunda deste modelo e leve a resultados interessantes no futuro. 


\section{Referências Bibliográficas}

[AMMZ10] F. A. Anta, A. Milani, M. Mosteiro e S. Zaks. Opportunistic information dissemination in mobile ad-hoc networks: The profit of global synchrony. Em Proceedings of the 24th International Symposium on Distributed Computing, páginas 374-388, 2010. 5

[ASSC02] I.F. Akyildiz, W. Su, Y. Sankarasubramaniam e E. Cayirci. Wireless sensor networks: a survey. Computer networks, 38(4):393-422, 2002. 1

$\left[\mathrm{AST}^{+} 10\right]$ L. Arantes, P. Sens, G. Thomas, D. Conan e L. Lim. Partition participant detector with dynamic paths in mobile networks. Em IEEE International Symposium on Network Computing and Applications, páginas 224-228, 2010. 5

[BAI94] B.R. Badrinath, A. Acharya e T. Imielinski. Structuring distributed algorithms for mobile hosts. Em 14th International Conference on Distributed Computing Systems, páginas 21-28, 1994. 2, 6

[BBRTP07] R. Baldoni, M. Bertier, M Raynal e S. Tucci Piergiovanni. Looking for a definition of dynamic distributed systems. Em Proceedings of the 16th International Conference on Parallel Architectures and Compilation Techniques, páginas 1-14, 2007. 5

[BCF09] H. Baumann, P. Crescenzi e P. Fraigniaud. Parsimonious flooding in dynamic graphs. Em Proceedings of the twenty-eighth ACM symposium on Principles of distributed computing, PODC '09, páginas 260-269, 2009. 5

[BGJL06] J. Burgess, B. Gallagher, D. Jensen e B.N. Levine. Maxprop: Routing for vehicle-based disruption-tolerant networks. Em Proceedings of the 27th Conference on Computer Communications, volume 6, páginas 1-11. Barcelona, Spain, 2006. 7, 35

[BHM07] R. Baumann, S. Heimlicher e M. May. Towards realistic mobility models for vehicular ad-hoc networks. Em 2007 Mobile Networking for Vehicular Environments, páginas 73-78. IEEE, 2007. 7

[BLV08] A. Balasubramanian, B.N. Levine e A. Venkataramani. Enhancing interactive web applications in hybrid networks. Em Proceedings of the 14th ACM international conference on Mobile computing and networking, páginas 70-80. ACM, 2008. 7, 35, 42

[BVP02] R. Baldoni, A. Virgillito e R. Petrassi. A distributed mutual exclusion algorithm for mobile ad-hoc networks. Em Proceedings of the 7th IEEE Symposium on Computers and Communications, páginas 539-545, 2002. 2, 6

[BXFJ02] B. Bui Xuan, A. Ferreira e A. Jarry. Computing shortest, fastest, and foremost journeys in dynamic networks. Relatório Técnico RR-4589, INRIA, Outubro 2002. 6, 11

[CCF10] A. Casteigts, S. Chaumette e A. Ferreira. Characterizing topological assumptions of distributed algorithms in dynamic networks. Structural Information and Communication Complexity, páginas 126-140, 2010. 2, 3, 6, 11, 13, 18 
$\left[\mathrm{CMM}^{+} 08\right]$ A. E.F. Clementi, C. Macci, A. Monti, F. Pasquale e R. Silvestri. Flooding time in edge-markovian dynamic graphs. Em Proceedings of the 27th ACM Symposium on Principles of Distributed Computing, PODC '08, páginas 213-222, 2008. 5

[CMPS09] A.E.F Clementi, A. Monti, F. Pasquale e R. Silvestri. Information spreading in stationary markovian evolving graphs. Em 23rd IEEE International Symposium on Parallel and Distributed Processing, páginas 1-12, 2009. 5

[cra] Crawdad - a community resource for archiving wireless data at dartmouth. http://crawdad.cs.dartmouth.edu. acessado em junho de 2011. 7, 35

[DFMSN01] C. Demetrescu, D. Frigioni, A. Marchetti-Spaccamela e U. Nanni. Maintaining shortest paths in digraphs with arbitrary arc weights: An experimental study. Algorithm Engineering, páginas 218-229, 2001. 5

[ESE06] S. Eichler, C. Schroth e J. Eberspächer. Car-to-car communication. Em VDE-Kongress 2006. VDE VERLAG GmbH, 2006. 1

[Fer02] A. Ferreira. On models and algorithms for dynamic communication networks: The case for evolving graphs. Em $4^{\circ}$ Rencontres Francophones sur les Aspects Algorithmiques des Télécomunications, páginas 155-161, 2002. 1, 5

[Fer04] A. Ferreira. Building a reference combinatorial model for manets. IEEE Network, 18(5):24-29, 2004. 6, 9

[FG11] P. Floriano e A. Goldman. An evaluation system: A step beyond dtn traces. Em 3rd Extreme Conference on Communication, 2011. 48

[FGA11] P. Floriano, A. Goldman e L. Arantes. Formalization of the necessary and sufficient connectivity conditions to the distributed mutual exclusion problem in dynamic networks. Em 10th IEEE International Symposium on Network Computing and Applications, páginas 203-210. IEEE, 2011. 48

[GFM10] A. Goldman, P.H. Floriano e C.G. Machado. Optimal journeys and trade-offs on dtns. Em 2nd Extreme Workshop on Communication, 2010. 6, 7, 36

[GFMF10] A. Goldman, C. Ferreira, C. Machado e P. Floriano. Jornadas mais rápidas e compromissos em DTNs. Em XXVIII Simpósio Brasileiro de Redes de Computadores e Sistemas Distribuídos, 2010. 7, 36

[HPR88] J. M. Helary, N. Plouzeau e M. Raynal. A distributed algorithm for mutual exclusion in an arbitrary network. Comput. J., 31:289-295, August 1988. 3

[KOK09] A. Keränen, J. Ott e T. Kärkkäinen. The ONE Simulator for DTN Protocol Evaluation. Em Proceedings of the 2nd International Conference on Simulation Tools and Techniques, New York, NY, USA, 2009. ICST. 7, 37

[Lam78] L. Lamport. Time, clocks, and the ordering of events in a distributed system. CACM, 21(7):558-564, 1978. 2, 9, 15

$\left[\mathrm{LFM}^{+} 10\right]$ A.A.F. Loureiro, A.C. Frery, R. Mini, ALL Aquino, H.S. Ramos e M.G. Almiron. Redes complexas na modelagem de redes de computadores. SBRC 2010 Minicursos, 2010. 5,37

[LS99] I. Litovsky e E. Sopena. Graph relabelling systems and distributed algorithms. Handbook of Graph Grammars and Computing by Graph Transformation. Concurrency, Parallelism, and Distribution, 3:1-56, 1999. 2, 6 
[MGF07] J. Monteiro, A. Goldman e A. Ferreira. Using evolving graphs foremost journey to evaluate ad-hoc routing protocols. Em XXV Simpósio Brasileiro de Redes de Computadores e Sistemas Distribuídos, páginas 17-30, 2007. 7

$\left[\mathrm{MRT}^{+} 05\right]$ A. Mostefaoui, M. Raynal, C. Travers, S. Patterson, D. Agrawal e A. El Abbadi. From static distributed systems to dynamic systems. Em Proceedings of the 24th IEEE Symposium on Reliable Distributed Systems, páginas 109-118, 2005. 5

[n4c] Networking for communications challenged communities - architecture, test beds and innovative alliances. http://www.n4c.eu/. acessado em junho de 2011. 1

[NT96] M. Naimi e M. Trehel. A $\log (\mathrm{n})$ distributed mutual exclusion algorithm based on the path reversal. Journal of Parallel and Distributed Computing, 34:1-13, 1996. 2

[RA81] G. Ricart e A.K. Agrawala. An optimal algorithm for mutual exclusion in computer networks. Communications of the ACM, 24(1):9-17, 1981. 2, 3, 16

[Ray89a] K. Raymond. A distributed algorithm for multiple entries to a critical section. Information Processing Letters, 30(4):189-193, 1989. 3, 30

[Ray89b] K. Raymond. A tree-based algorithm for distributed mutual exclusion. ACM Transactions on Computer Systems, 7(1):61-77, 1989. 2

[SK85] I. Suzuki e T. Kasami. A distributed mutual exclusion algorithm. ACM Transactions on Computer Systems, 3(4):344-349, 1985. 2

$\left[\mathrm{SMM}^{+} 11\right]$ S. Scellato, M. Musolesi, C. Mascolo, V. Latora e A.T. Campbell. Nextplace: A spatiotemporal prediction framework for pervasive systems. Pervasive Computing, 6696:152169, 2011. 7

[SMSC11] N. Sastry, D. Manjunath, K. Sollins e J. Crowcroft. Data delivery properties of human contact networks. IEEE Transactions on Mobile Computing, (6):868-880, 2011. 7

[uma] Umass trace repository. http://traces.cs.umass.edu/. acessado em junho de 2011. 7, 35

[WWV01] J. E. Walter, Jennifer L. Welch e N. H. Vaidya. A mutual exclusion algorithm for ad hoc mobile networks. Wireless Networks, 7:585-600, 2001. 2, 6 